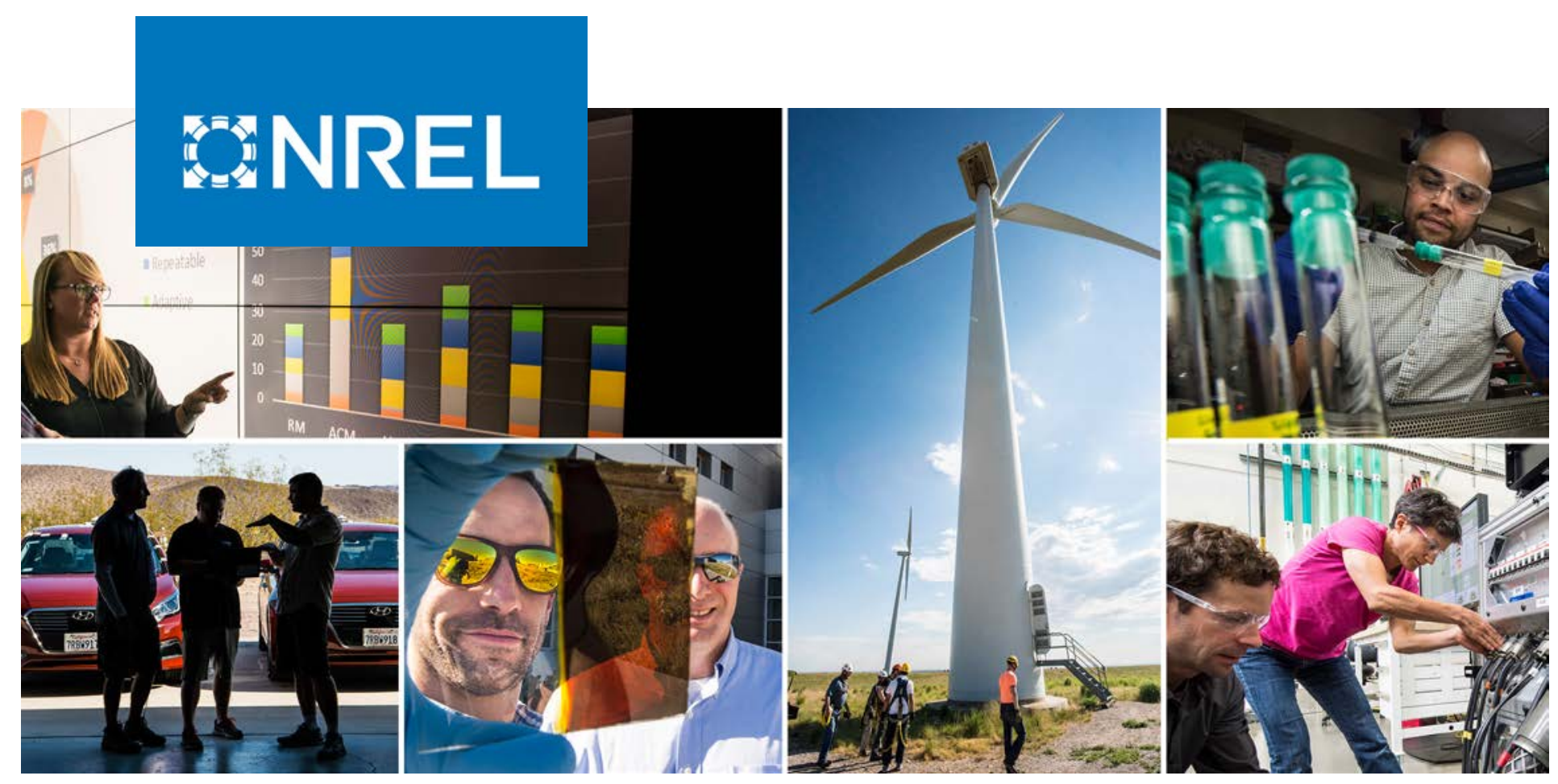

\title{
Telematics and Data Science: Informing Energy-Efficient Mobility
}

Ryan Daley and Matthew Helm

Sawatch Group, LLC

NREL Technical Monitor: Ted Sears

NREL is a national laboratory of the U.S. Department of Energy

Office of Energy Efficiency \& Renewable Energy

Operated by the Alliance for Sustainable Energy, LLC

This report is available at no cost from the National Renewable Energy Laboratory (NREL) at www.nrel.gov/publications.
Subcontract Report NREL/SR-5400-73661 August 2019 


\title{
GNREL
}

\section{Telematics and Data Science:} Informing Energy-Efficient Mobility

\author{
Ryan Daley and Matthew Helm
}

Sawatch Group, LLC

NREL Technical Monitor: Ted Sears

\section{Suggested Citation}

Daley, Ryan and Matthew Helm. 2019. Telematics and Data Science: Informing Energy-Efficient Mobility. Golden, CO: National Renewable Energy Laboratory. NREL/SR-5400-73661. https://www.nrel.gov/docs/fy19osti/73661.pdf.

NREL is a national laboratory of the U.S. Department of Energy Office of Energy Efficiency \& Renewable Energy Operated by the Alliance for Sustainable Energy, LLC

This report is available at no cost from the National Renewable Energy Laboratory (NREL) at www.nrel.gov/publications.

Contract No. DE-AC36-08GO28308
Subcontract Report NREL/SR-5400-73661 August 2019

National Renewable Energy Laboratory 15013 Denver West Parkway Golden, CO 80401 303-275-3000 • www.nrel.gov 


\section{NOTICE}

This work was authored in part by the National Renewable Energy Laboratory, operated by Alliance for Sustainable Energy, LLC, for the U.S. Department of Energy (DOE) under Contract No. DE-AC36-08GO28308. Funding provided by U.S. Department of Energy Office of Energy Efficiency and Renewable Energy Vehicle Technologies Office. The views expressed herein do not necessarily represent the views of the DOE or the U.S. Government.

This report is available at no cost from the National Renewable Energy Laboratory (NREL) at www.nrel.gov/publications.

U.S. Department of Energy (DOE) reports produced after 1991 and a growing number of pre-1991 documents are available free via www.OSTI.gov.

Cover Photos by Dennis Schroeder: (clockwise, left to right) NREL 51934, NREL 45897, NREL 42160, NREL 45891, NREL 48097, NREL 46526.

NREL prints on paper that contains recycled content. 


\section{Telematics \& Data Science: Informing Energy-Efficient Mobility}

Fleets exploring the possibility of adding electric vehicles (EVs) (battery EVs (BEVs) and plugin hybrid electric vehicles (PHEVs)) seek an efficient, data-driven means to estimate both expenditures for vehicle and charging infrastructure and the appropriate placement of them to help ensure the cost-effective adoption of these technologies. Exploring data collection and analytic methodologies across different telematics providers offers the opportunity to better understand the strengths, weaknesses, and possibilities for employing different methods of data collection, including smartphone-based telematics and more traditional telematics with hardware installed on a vehicle's onboard diagnostics port. This report presents results of five pilot programs that collected data from the operation of conventional light-duty fleet vehicles to generate estimates for transitioning these fleet vehicles to EVs, implementing charging infrastructure, and establishing management practices to maximize the benefits of these new fleet technologies. 


\section{Acknowledgements}

This study was supported by the U.S. Department of Energy (DOE) Vehicle Technologies Office Alternative Fuel Transportation Program, as managed by the National Renewable Energy Laboratory (NREL). The program, also referred to as the State and Alternative Fuel Provider Fleet Program, offers assistance to covered fleets as they work to achieve compliance with their requirements under the Energy Policy Act (EPAct), as implemented via the program. The program, as with other EPAct transportation-related programs at DOE, aims to increase alternative fuel use by supporting alternative fuel vehicle availability and related infrastructure. This work was completed under a contract between NREL and Sawatch Labs. The authors would like to thank fleet-management personnel at the following organizations:

- State of Louisiana Department of Environmental Quality

- Florida Power \& Light

- University of Connecticut ${ }^{1}$

- State of Rhode Island

- State of Colorado.

The authors would also like to thank NREL expert Ted Sears. All judgments in the final analytic methodologies and interpretations were developed by and are the responsibility of Sawatch Labs and not of the persons acknowledged above.

\footnotetext{
${ }^{1}$ This work is an extension of work addressed in an earlier publication regarding the pilot analysis specific to UConn: https://www.nrel.gov/docs/fy18osti/69018.pdf
} 


\section{List of Acronyms}

$\begin{array}{ll}\text { BEV } & \text { battery electric vehicle } \\ \text { DC } & \text { direct current } \\ \text { DNR } & \text { Department of Natural Resources } \\ \text { DOE } & \text { U.S. Department of Energy } \\ \text { DOT } & \text { Department of Transportation } \\ \text { EPAct } & \text { Energy Policy Act } \\ \text { EV } & \text { electric vehicle } \\ \text { EVSA } & \text { EV Suitability Assessment } \\ \text { EVSE } & \text { electric vehicle supply equipment } \\ \text { FPL } & \text { Florida Power \& Light } \\ \text { GHG } & \text { greenhouse gas } \\ \text { GPS } & \text { global positioning system } \\ \text { ICE } & \text { internal combustion engine } \\ \text { kWh } & \text { kilowatt-hour } \\ \text { LDEQ } & \text { Louisiana Department of Environmental Quality } \\ \text { MPH } & \text { miles per hour } \\ \text { MTCO } & \text { metric tons of carbon dioxide equivalent } \\ \text { NREL } & \text { National Renewable Energy Laboratory } \\ \text { PHEV } & \text { plug-in hybrid electric vehicle } \\ \text { Sawatch } & \text { Sawatch Labs } \\ \text { TCO } & \text { total cost of ownership } \\ \text { UConn } & \text { University of Connecticut } \\ \text { VMT } & \text { vehicle miles traveled } \\ & \end{array}$




\section{Executive Summary and Recommendations}

The State and Alternative Fuel Provider Fleet Program at the National Renewable Energy Laboratory (NREL) worked with Sawatch Labs (Sawatch) to analyze fleet vehicle suitability for transition to electric vehicles (EVs) and pilot the use of telematics data to perform the analysis. This effort supported improved understanding of how fleets mandated under the Energy Policy Act of 1992 (EPAct) could use such information to support the acquisition of alternative fuel vehicles, or otherwise implement strategies to increase alternative fuel use. Data collection and analyses were completed for five EPAct-covered fleets that included vehicles from four states (Louisiana, Connecticut, Rhode Island, and Colorado), and one utility (Florida Power \& Light (FPL)).

The pilot projects were initiated with the intent to use a smartphone-based mobile application to collect telematics data from fleet vehicles and drivers. Initial conversations with fleet managers quickly revealed that some fleets already collect these data via other providers, in most instances using more traditional telematics devices connected to the vehicle's onboard diagnostics port. To work with these fleets, Sawatch created a data-source-agnostic platform to work with any fleet collecting telematics data, regardless of provider.

With data in hand, whether collected via smartphone or traditional telematics hardware, and using Sawatch's ezEV analytics package, each fleet was provided with an analysis of its vehicles' suitability for transition to an EV. These analytics use telematics data to translate drive cycles and driving behavior for individual fleet vehicles into an EV Suitability score for each vehicle assessed. Each fleet project employed slightly different data collection methods, with varying vehicle use profiles and resulting recommendations for EV adoption. Data collection methods were broadly successful, with one exception: the method employed in Rhode Island was limited in its ability to generate an EV suitability assessment.

Data collection efforts reveal that smartphone-based data collection can be a valuable, low-cost tool where fleets have not yet made their own investments in more traditional telematics. Nonetheless, smartphones are not a sufficient replacement for traditional telematics technology. Instead, the two can complement one-another.

The duty cycles of each pilot project varied significantly, revealing both opportunities and challenges for the deployment of EVs into the fleets examined. EV placement recommendations were limited and may depend on changes to vehicle management/assignment for fleets with large geographic footprints such as Colorado and Louisiana. This could require ensuring that specific driving routes are placed on EVs while long-distance and overnight trips to rural and more remote parts of those states are driven in a plug-in hybrid electric vehicle (PHEV) or internal combustion engine (ICE) vehicle.

Conversely, fleets with more compact geographies, like those examined in Rhode Island and Connecticut, had better opportunities for EV deployment based on their operational profiles but saw significantly lower usage of vehicles overall in terms of total miles driven. The lower vehicles miles traveled could complicate these fleets' ability to generate a sufficient return on their investment in EV technology in a reasonable amount of time. On the other hand, the FPL fleet vehicles, operating on a service territory duty cycle, exhibited high-mileage vehicles 
operating in known geographies with fairly consistent operational needs. Many of its duty cycles present good opportunities for EVs given the combination of high-mileage vehicles, minimal long-distance travel, and frequent access to facilities with existing charging infrastructure.

The results of this study suggest additional lines of inquiry, examinations that might best be undertaken with the Colorado fleet given its critical mass of EVs in operation and available data compared with the other four fleets that were part of this study. Such an examination would seek to: (1) demonstrate the value of collecting, analyzing, and monitoring EV-specific data related to vehicle state-of-charge and charging patterns; (2) compare real-world vehicle performance to ezEV estimates; (3) validate the ability of fleets to incorporate new technology-e.g., kWh consumption and electricity costs alongside gasoline consumption and costs - into existing accounting/financial systems; and (4) establish best practices that help ensure overall costs of integrating new vehicle technologies remain at or below cost parity with existing technologies. 


\section{Table of Contents}

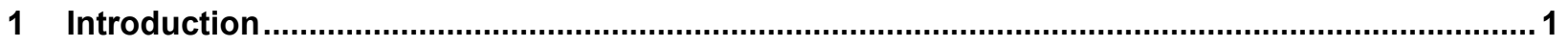

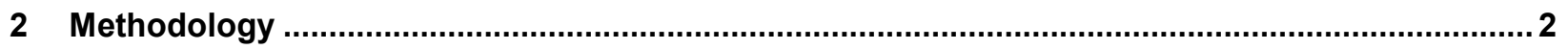

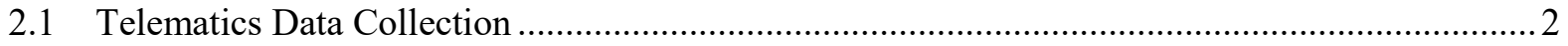

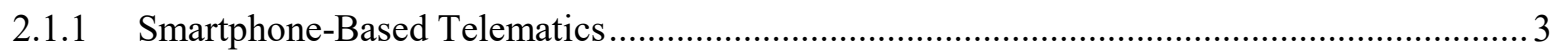

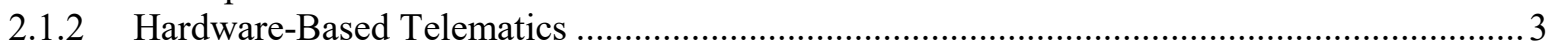

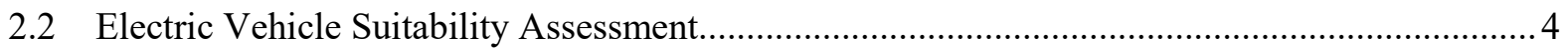

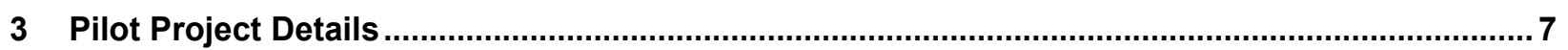

3.1 Louisiana Department of Environmental Quality …................................................................

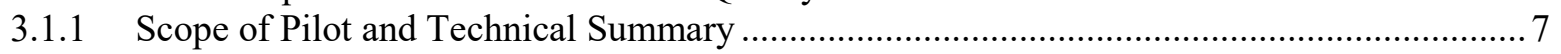

3.1.2 Fleet Characteristics ................................................................................... 7

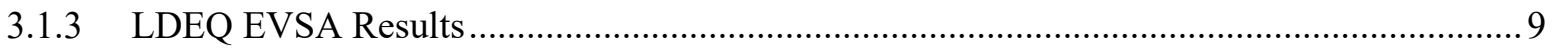

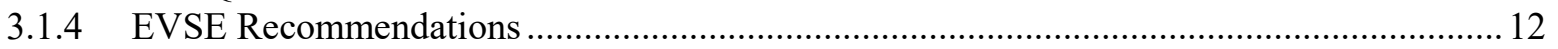

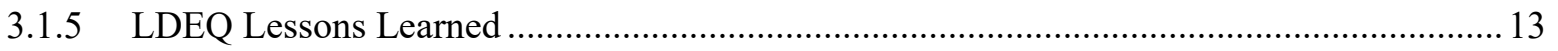

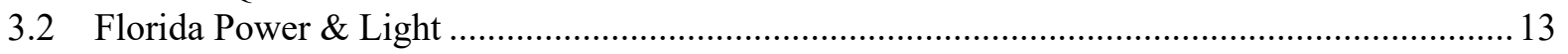

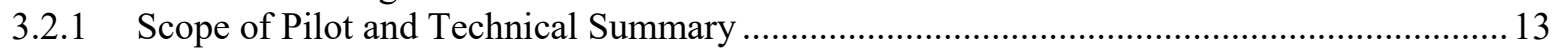

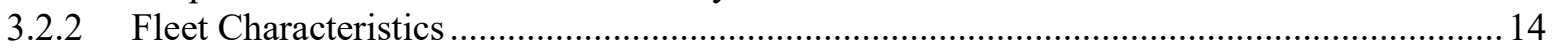

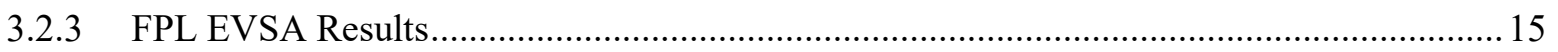

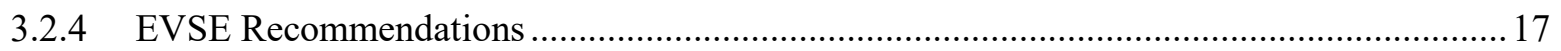

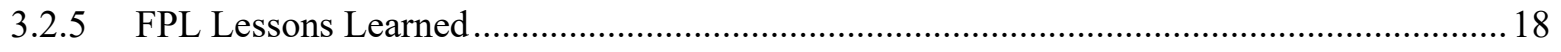

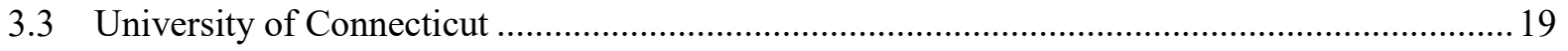

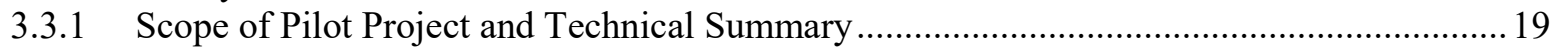

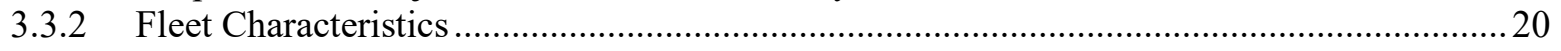

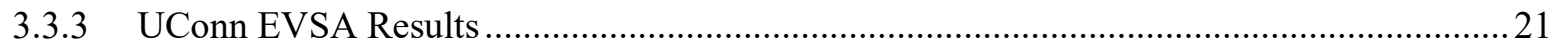

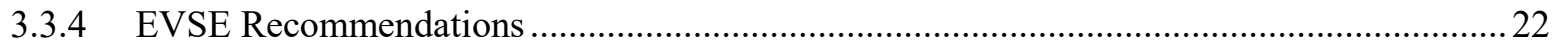

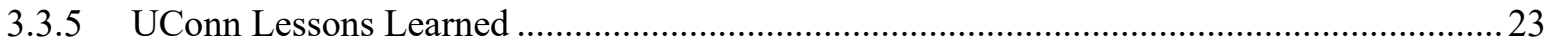

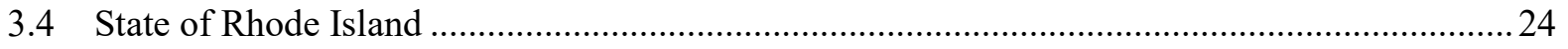

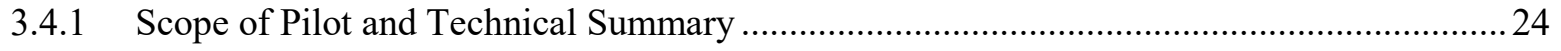

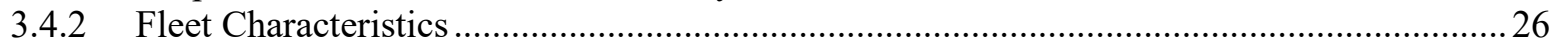

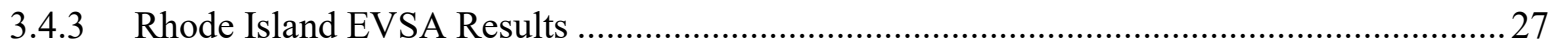

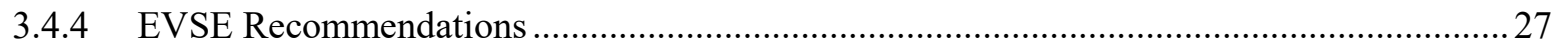

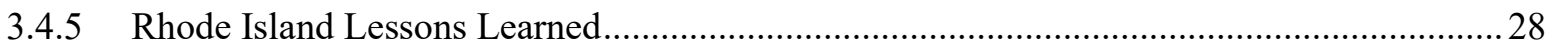

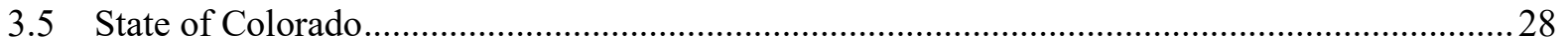

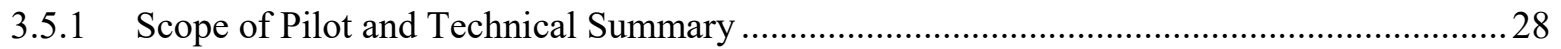

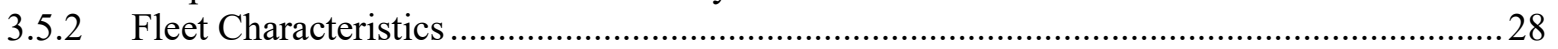

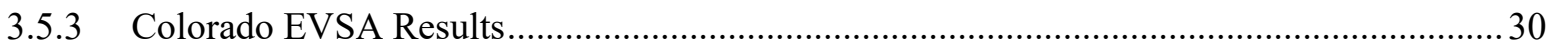

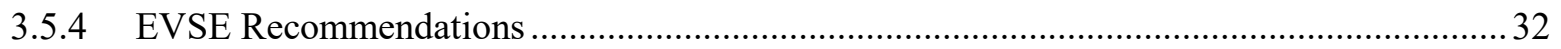

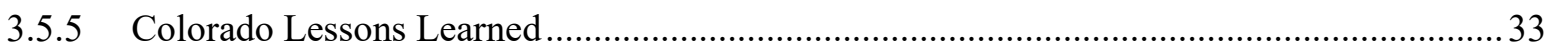

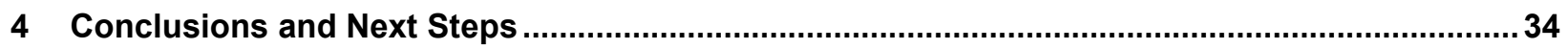




\section{List of Figures}

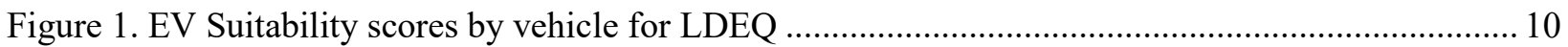

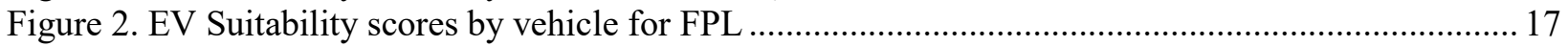

Figure 3. Vehicle trip ending locations relative to existing EVSE on UConn campus............................2 23

Figure 4. EV Suitability scores by vehicle for Colorado ................................................................... 31

\section{List of Tables}

Table 1. Selected Data Fields Available from Telematics..................................................................... 2

Table 2. Summary GPS Insight Data Averages by Division/Office - LDEQ ….................................. 8

Table 3. Per-Vehicle GPS Insight Averages for September-November 2016 ....................................... 8

Table 4. Per-Vehicle Lifetime Averages as of November 2016 - LDEQ ................................................ 9

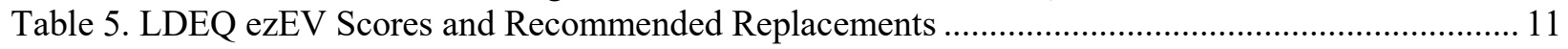

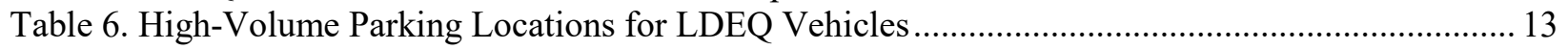

Table 7. Individual Vehicle Use Averages, June 1-September 1, 2017 ................................................ 15

Table 8. EV and EVSE Recommendations for FPL Vehicles ........................................................... 18

Table 9. UConn Individual Vehicle Use Averages, June 1-September 1, 2017.................................... 21

Table 10. Differences in Energy Use and Overall EV Suitability Scores across Select EVs .................... 22

Table 11. Summary of Data Averages Collected from October 17-December 20, 2017 ....................... 26

Table 12. EV and EVSE Recommendations for Rhode Island Vehicles .............................................. 27

Table 13. Individual Vehicle Use Averages for Colorado, June 1-September 1, 2017 ......................... 29

Table 14. EV and EVSE Recommendations for Colorado Vehicles ................................................... 30 


\section{Introduction}

Certain state and alternative fuel provider fleets are mandated under the Energy Policy Act of 1992 (EPAct) to acquire alternative fuel vehicles or otherwise implement strategies to increase alternative fuel use in covered fleet vehicles. ${ }^{2}$ The U.S. Department of Energy's (DOE's) Vehicle Technologies Office implements these provisions via the Alternative Fuel Transportation Program, also known as the State and Alternative Fuel Provider Fleet Program, with the assistance of the National Renewable Energy Laboratory (NREL). The analytical efforts NREL undertakes can be helpful to covered fleets working to achieve their EPAct compliance requirements.

The State and Alternative Fuel Provider Fleet Program began working with Sawatch Labs (Sawatch) to analyze fleet vehicle suitability for transition to electric vehicles (EVs) and pilot the use of telematics data to perform the analysis. An unforeseen outcome of these pilots was the opportunity to test data collection and analytic methodologies across different telematics providers to better understand the strengths, weaknesses, and possibilities for employing different methods of data collection. Data were collected using both smartphone-based telematics and more traditional telematics with hardware installed on the vehicles' onboard diagnostics ports.

The approach in this pilot project involved collecting data from fleet vehicles, and then using the Sawatch analytics platform, ezEV, to analyze vehicle performance, routing, and location data to: (1) determine the suitability of each vehicle monitored for transition to an EV; (2) identify the electric vehicle supply equipment (EVSE), also known as charging infrastructure, needed to match the driving needs of these vehicles should they be transitioned to EVs; and (3) provide guidance on EV total cost of ownership (TCO), return on investment, and potential cost savings.

Five EPAct-covered fleet organizations partnered with NREL and Sawatch as participants in the pilot program. Those organizations are:

- State of Louisiana Department of Environmental Quality (LDEQ)

- Florida Power \& Light (FPL)

- University of Connecticut ${ }^{3}$ (UConn)

- State of Rhode Island

- State of Colorado.

Each of these organizations received a summary report of the analysis specific to its fleet. This report summarizes those efforts and the varying data collection methods used to complete the pilot program for each.

\footnotetext{
${ }^{2}$ https://epact.energy.gov/

${ }^{3}$ This work is an extension of work addressed in an earlier publication regarding the pilot analysis specific to UConn: https://www.nrel.gov/docs/fy18osti/69018.pdf
} 


\section{Methodology}

This section describes the methods used in the study.

\subsection{Telematics Data Collection}

In fleet management, the term "telematics" broadly refers to two interrelated technologies: tracking the location, movement, and performance of motor vehicles; and the long-distance transmission of these data. The resulting datasets include a global positioning system (GPS) trace of vehicle activity as well as vehicle and engine performance data, driver behavior, and more. Table 1 provides an overview of some available data fields as well as some fields Sawatchgenerated data that were used in analyzing vehicle compatibility with new fuel technologies.

Table 1. Selected Data Fields Available from Telematics

\begin{tabular}{ll}
\hline Telematics & Telematics + Sawatch Analytics \\
\hline Vehicle location & Miles per trip/duty cycle/day/month \\
Odometer readings & Average and maximum miles per day \\
Diagnostic trouble codes & Fuel consumption \\
Vehicle uptime and downtime & Fuel economy \\
Total distance travelled & Idle fuel consumption \\
Vehicle speed (average, max, and time & $\begin{array}{l}\text { Greenhouse gases (GHG) and other } \\
\text { spent above certain speed thresholds) }\end{array}$ \\
Engine idle time & Utilization rates \\
Hard braking & Overnight parking locations \\
Hard accelerating & \\
\hline
\end{tabular}

Despite the existence of vehicle telematics in the commercial market for more than 20 years, the vehicle telematics market is not fully saturated. As the pilot projects commenced, it became clear that there would be some fleets in the pilot projects with existing telematics and others that would need telematics data collected to complete an analysis of their fleet vehicles for conversion to EVs. This fact enabled the exploration of various methods of and costs associated with collection of telematics data from various sources. For the pilot program, telematics data were gathered through one of two ways: Sawatch's smartphone-based telematics, and more traditional hardware-based telematics devices. 


\subsubsection{Smartphone-Based Telematics}

Four of the five fleets in the pilot used ezEV-Fleet software installed on smartphones to collect telematics data. ezEV-Fleet uses Sawatch's PTRTelematics framework to capture vehicle telemetry. ${ }^{4}$ PTRTelematics serves as the framework for all Sawatch's driving telemetry software applications, including the consumer-facing version of ezEV and the Petrolr consumer brand telematics product. Rather than gather telemetry data in the traditional way-plugging hardware into the onboard diagnostic port to communicate with the vehicle's computer, the engine control unit_PTRTelematics uses a smartphone's internal sensors to derive vehicle activity and performance.

Much of the functionality incorporated in traditional telematics hardware components is included in contemporary smartphones. The sensors most often used in traditional telematics include a GPS to track location data, an accelerometer for hard braking/hard acceleration and accident detection, a data/cellular connection for data transmission, and a hardwired connection to the vehicle's engine control unit to capture vehicle performance. Of these functions, the GPS, accelerometer, and data connectivity functions of an Android or iOS smartphone are in many cases able to capture data with increased frequency and sensitivity and transmit the data at a lower cost.

Smartphone-based telematics, however, cannot match the hardwired connection to the vehicle's electronics inherent in traditional telematics hardware. For this, PTRTelematics models vehicle performance through a variety of stochastic methods and through use of low-energy Bluetooth radio beacons, which are placed in the vehicle and powered through the vehicle's direct current (DC) outlet. The radio beacon indicates that the vehicle's engine is running and-through use of an identifier on the radio signal-identifies in which vehicle the data-collecting smartphone is located and that it should start collecting data on the vehicle's movement.

For the four pilot fleets using ezEV-Fleet to collect telematics data, the mobile app was installed on smartphones that were either (1) placed in a vehicle and intended to remain in the vehicle for the duration of the study, or (2) remained with the driver. Bluetooth radio beacons were placed inside each vehicle. When a vehicle was started, the radio beacon activated, and the software on the phone became active and monitored the vehicle's activity.

\subsubsection{Hardware-Based Telematics}

For two of the fleets in the pilot projects, data were collected using more traditional telematics hardware that is plugged into each vehicle's onboard diagnostics port. ${ }^{5}$ In these scenarios, it is common for a fleet to purchase the telematics hardware, install it in each vehicle, and then pay for recurring monthly data subscriptions to transmit that data to a central repository. With the hardwired connection to the vehicle's onboard computers, these telematics devices and packages have the added functionality of data capture that includes engine diagnostics, health, and trouble codes. Today's computers embedded in vehicles also allow for the capture of other contextual vehicle operation data, such as seatbelt use, door opening and closing, and windshield wiper use, among others. These additional data points are useful for a variety of fleet management purposes.

\footnotetext{
4 The app can be viewed at https://itunes.apple.com/us/app/ezev/id1113728520? $1 \mathrm{~s}=0 \& \mathrm{mt}=8$

${ }^{5}$ Colorado used smartphone-based telematics for some of their vehicles and hardware-based telematics for others.
} 
One primary benefit of traditional telematics over smartphone telematics is avoidance of the uncertainty the human element may introduce. Traditional telematics are hardwired into the vehicles and typically hidden from view of vehicle operators. This fact eliminates human factors that can plague data collection using smartphones; with humans involved, the phone battery collecting the data runs out, the phone is left at home, Bluetooth is turned off, the beacon is removed, not all drivers have adequate smartphones, and even a phone left in the vehicle in cold weather causing the phone's battery to deplete rapidly are possible scenarios. All of these elements are moot when using telematics hardware that is plugged directly into the vehicle. Of course, hardware-based telematics may be more expensive, are not infallible to interruptions in data collection, and hardware failure is still a possibility.

\subsection{Electric Vehicle Suitability Assessment}

The Sawatch analytics package is data-source agnostic: it can run with any telematics providers' data. Consequently, in these pilot projects, the Sawatch analytics represent the constant attribute, and the different telematics data collection methods examined were variable. Sawatch developed ezEV analytics to use telematics data to translate drive cycles and driving behavior for individual fleet vehicles into an EV Suitability score for each vehicle assessed regardless of the collection method. This methodology explains vehicle use and driving style in the context of impact on vehicle performance as if the vehicle operator were driving an EV, doing so across four metrics contributing to an overall EV Suitability score. Each metric is based on a score of 1 to 100 . Lower scores do not necessarily indicate that an EV would not work in a particular application or duty cycle. Instead, lower scores suggest that modifying driving habits and/or identifying where midday charging could take place may be necessary for EVs to meet the current demands on that vehicle. The scoring components are:

- Overall Score: Considering a combination of the categories below, how well each vehicle is suited for transition to an EV. An overall score of 85 or higher typically indicates a very good EV candidate.

- Confidence: The degree to which an available dataset constitutes a representative sample of driving.

- Energy Use: How often a vehicle could rely on a single daily charge, eliminating the need for midday charging and assuming that the vehicle would start with a fully charged battery each day.

- Speed: The amount of time driven at lower speeds - frequent travel at highway speeds can reduce the range of a battery electric vehicle $(\mathrm{BEV})$ or the all-electric range of a plugin hybrid electric vehicle (PHEV).

- Efficiency: The impact of driving style on a vehicle's efficiency-how aggressively an EV is driven affects the vehicle's actual miles per kilowatt-hour in an EV in the same way that driving style affects miles per gallon in a conventional internal combustion engine (ICE) vehicle.

The scores can be used to provide a degree of certainty in a fleet manager's decision to replace an ICE vehicle with an electric-drive vehicle. Electric-drive vehicles effectively come in two varieties, BEVs and PHEVs. They differ primarily in the form of fuel or energy they store on board and can access when they are driving, and as a result differ in the distance they can travel 
when fully fueled. BEVs have energy in the form of electricity that is stored in a battery on board the vehicle. The size or capacity of the battery limits the range that the vehicle can travel on a single charge. For drivers and fleet managers, limited range can lead to "range anxiety," or the concern that the vehicle will run out of energy before returning to the vehicle's charging location. PHEVs have both a battery, typically smaller than a BEV's battery, and a conventional ICE that runs on liquid petroleum fuel. As a result, drivers of PHEVs do not experience range anxiety because they can add fuel to the tank at nearly any service station.

Each of the five pilot projects conducted in this analysis used an early version of the Sawatch ezEV platform. In this version, all vehicles were analyzed against a generic BEV with a $27-$ kilowatt-hour $(\mathrm{kWh})$ battery and $24 \mathrm{kWh}$ of usable battery capacity ${ }^{6}$ and are assumed to charge at a rate of $5.4 \mathrm{~kW}$ per hour using Level 2 EVSE. ${ }^{7}$ Lessons learned from these pilots drove significant improvements in the ezEV analytics and vehicle modeling in each successive fleet pilot project that is addressed in this report. While they are not discussed in great detail here, these improvements included more detailed recommendations around EVSE siting and the inclusion of economics and infrastructure scoring in the model. Later versions also remove the speed and efficiency scores as they were found to be largely redundant and already captured in the Energy Use scoring.

Additional factors that do not contribute to the overall score generated by the ezEV model but which may be considered in addition to the ezEV model scoring include greenhouse gas (GHG) emissions, driver behavior, operational characteristics, EVSE siting, and TCO of individual vehicles. These metrics also include things like annual vehicle miles traveled (VMT) and instances of long-distance or overnight travel, which greatly impact recommendations to adopt EVs when more than one full battery charge in an EV would be used. GHG emissions is an additional output that can be generated from the ezEV model, if the fleet is interested in this feature and calculation/result. These attributes are described in greater detail in an earlier publication that explored the University of Connecticut (UConn) pilot project. ${ }^{8}$

\subsubsection{Electric Vehicle Supply Equipment}

An inherent benefit of telematics is the collection of location data. These data are not only useful to understand where a vehicle travels, but also to better understand where vehicles regularly park, especially overnight. The data allow fleets to make an informed decision about the number of Level 2 EVSE that need to be installed in support of the EVs that are to be deployed. By optimizing the number of Level 2 chargers installed, it is possible to reduce the amount of infrastructure needed and, as a result, overall project costs.

To evaluate infrastructure needs, ezEV characterizes each trip by duration, estimated electricity use, and starting and ending location. The same metrics are calculated and compiled for each

\footnotetext{
${ }^{6} \mathrm{EV}$ batteries are rated in terms of "battery capacity," or the total amount of energy the battery can store. The amount of energy a vehicle can use in real-world driving conditions is generally $80 \%-90 \%$ of the battery's total capacity. The usable energy of the generic BEV is averaged across the 2017 Nissan Leaf, Ford Focus EV, BMW i3, and Kia Soul EV.

${ }^{7}$ Level 2 EVSE refers to equipment that will charge a vehicle through a 240 -volt (V) electrical service, Level 1 charging refers to a $120-\mathrm{V}$ service or outlet, and DC fast charging requires $480-\mathrm{V}$ service. Additional information on EVSE definitions is available at https://www.afdc.energy.gov/fuels/electricity infrastructure.html.

${ }^{8}$ See infra fn 3.
} 
individual day that a vehicle operates. We focus specifically on overnight parking locations and durations, estimating the amount of time that would be needed to fully recharge each vehicle after a day's worth of driving. 


\section{Pilot Project Details}

Data were collected using five different methods for these pilot programs. For four of the projects in this pilot (Colorado, FPL, Rhode Island, and UConn), the ezEV smartphone app was installed on smartphones to collect telematics data. Two of the pilot projects used telematics hardware installed on the vehicles from two different vendors: GPS Insight (Louisiana) and Geotab (Colorado). GPS Insight was selected by the State of Louisiana prior to this project to collect fleet data across the fleet. The State of Colorado selected Geotab, which supported the second phase of this pilot, in large part due to its ability to collect EV-specific data, i.e., battery state of charge and individual charging events. The breakdown of data collection methods by project is as follows:

1. iPhones already issued to drivers from the employer (FPL and Colorado)

2. iPhone 5C placed into individual ICE vehicles for the duration of the study (UConn and Colorado)

3. LG Rebel 2 phones running Android placed into individual ICE vehicles for the duration of the study (Rhode Island)

4. GPS Insight devices already installed on individual ICE vehicles (Louisiana)

5. Geotab devices installed on motor pool ICE vehicles and EVs (Colorado).

The following sections provide an overview of each pilot project, the scope of the project, a technical summary, and baseline operational data, as well as the results of the EV Suitability Assessment (EVSA).

\subsection{Louisiana Department of Environmental Quality}

\subsubsection{Scope of Pilot and Technical Summary}

The dataset LDEQ made available to Sawatch in January 2017 included GPS Insight telematics data captured between September 1 and November 30, 2016, for a total of 102 vehicles. No additional data were collected for this fleet. This period represents real-world driving conditions and is assumed to reflect normal operating characteristics such that these data are typical of annual duty cycles and fleet driving needs of LDEQ personnel. For the period of data provided, GPS Insight telematics captured 17,000 hours of driving activity, 13,000 trips, and 302,000 miles of vehicle telemetry in the monitored LDEQ vehicles.

\subsubsection{Fleet Characteristics}

The vehicles participating in the pilot were assigned to five divisions/offices within LDEQ. Some general characteristics of these vehicles, with totals by department, are provided in Table 2. These vehicles averaged nearly 3,000 miles during the 91-day study data period, which projects to just under 12,000 miles per vehicle annually (see Table 3 and Table 4). This is a relatively high-mileage fleet compared to other public sector fleets, which in turn presents both opportunities and challenges for a transition to EVs. These miles, however, are not evenly 
distributed across individual vehicles within the divisions. VMT in individual vehicles during this time frame ranged from a low of 151 miles to a high of 7,160. The number of trips per vehicle was also not distributed evenly, with a low of 13 in one vehicle and a high of 324 in another, suggesting that some vehicles are not used much at all (i.e., low-use vehicles). Average trip lengths ranged from 4.9 to 48 miles. Table 3 shows the per vehicle averages across the five divisions covered in this analysis

Table 2. Summary GPS Insight Data Averages by Division/Office - LDEQ

\begin{tabular}{llllll}
\hline Division/Office & Vehicles & Trips & $\begin{array}{l}\text { Avg. Days in } \\
\text { Operation } \\
\text { (per veh) }\end{array}$ & $\begin{array}{l}\text { Total } \\
\text { VMT }\end{array}$ & $\begin{array}{l}\text { Fuel } \\
\text { Used } \\
\text { (gal) }\end{array}$ \\
\hline $\begin{array}{l}\text { OEC Assessment } \\
\text { Division }\end{array}$ & 36 & 5,316 & 81 & 116,038 & 9,567 \\
$\begin{array}{l}\text { OEC Inspection Division } \\
\text { OEC UST and }\end{array}$ & 43 & 4,463 & 82 & 100,775 & 8,101 \\
$\begin{array}{l}\text { Remediation } \\
\text { Management and }\end{array}$ & 12 & 1,522 & 67 & 42,752 & 3,371 \\
$\begin{array}{l}\text { Finance } \\
\text { Office of the Secretary }\end{array}$ & 5 & 1,021 & 87 & 27,833 & 1,825 \\
\hline TOTALS & 102 & 12,908 & 397 & 14,827 & 1,160 \\
\hline
\end{tabular}

$\mathrm{MTCO}_{2} \mathrm{e}$ : metric tons of carbon dioxide equivalent OEC: Office of Environmental Compliance

UST: Underground Storage Tank

Table 3. Per-Vehicle GPS Insight Averages for September-November 2016

\begin{tabular}{lllll}
\hline Department/Division & Trips & $\begin{array}{l}\text { Avg. } \\
\text { Days in } \\
\text { Operation } \\
\text { (per veh) }\end{array}$ & VMT & $\begin{array}{l}\text { Fuel } \\
\text { Used } \\
\text { (gal) }\end{array}$ \\
\hline OEC Assessment Division & 148 & 41 & 3,223 & 266 \\
OEC Inspection Division & 104 & 32 & 2,344 & 188 \\
OEC UST and Remediation & 127 & 35 & 3,563 & 281 \\
Management and Finance & 170 & 49 & 4,639 & 304 \\
Office of the Secretary & 117 & 33 & 2,965 & 231 \\
Agency Averages & 127 & 37 & 2,963 & 236 \\
\hline
\end{tabular}

The data provided include some insight into the lifetime use of LDEQ fleet vehicles. Overall, this pool of vehicles is relatively old. The LDEQ lifetime operational data are summarized in Table 4. In terms of use, a significant amount of state-wide travel ensures that these vehicles are heavily used; many have lifetime VMT of more than 150,000 miles. Because the economic benefits of EVs are realized in their lower operating costs, it is common that a fleet would only realize a return on the higher upfront acquisition costs of EVs by maximizing the number of miles they drive over the lifetime of the EV. Accordingly, a fleet analysis that only considered operation data aggregated across months or years would identify nearly every LDEQ vehicle as a 
ripe candidate for replacement with an $\mathrm{EV}$, as they typically recommend that fleets replace their oldest, least efficient, and highest mileage vehicles with EVs. The value of a telematics analysis like this one lies in the ability to look at more granular data for the specific operations of each vehicle when determining which are best suited for transition to EV technology.

Table 4. Per-Vehicle Lifetime Averages as of November 2016 - LDEQ

\begin{tabular}{llllll}
\hline Department/Division & $\begin{array}{l}\text { Average } \\
\text { Age }\end{array}$ & $\begin{array}{l}\text { Average } \\
\text { VMT }\end{array}$ & $\begin{array}{l}\text { Average } \\
\text { Annual VMT }\end{array}$ & $\begin{array}{l}\text { Max } \\
\text { VMT }\end{array}$ & $\begin{array}{l}\text { Min. } \\
\text { VMT }\end{array}$ \\
\hline OEC Assessment Division & 9.5 & 117,819 & 12,810 & 248,733 & 6,036 \\
OEC Inspection Division & 10.6 & 119,249 & 11,226 & 201,697 & 17,514 \\
OEC UST and Remediation & 11.8 & 168,970 & 14,482 & 208,016 & 108,300 \\
Management and Finance & 11.4 & 176,621 & 15,217 & 251,855 & 111,479 \\
Office of the Secretary & 9.9 & 135,453 & 13,857 & 236,752 & 33,579 \\
Agency Averages & 10.7 & 143,623 & 13,519 & 229,411 & 55,382 \\
\hline
\end{tabular}

\subsubsection{LDEQ EVSA Results and Recommendations}

The 102 vehicles in the LDEQ fleet include a range of different vehicle sizes and types, but the majority of these vehicles are large sport utility vehicles (SUVs) like the Dodge Durango and Chevrolet Suburban and pickup trucks like the Dodge Ram and Chevrolet Silverado. These vehicles comprise nearly three-quarters of the LDEQ fleet and miles captured during the 91-day study period. Assuming the passenger and cargo carrying space in these vehicles is necessary for their missions and because commercially available, light-duty EVs as of May 2017 when the study began remained limited to sedans, this study narrowed its focus from the 102 total vehicles analyzed to the 27 sedans, minivans, and small SUVs in the LDEQ fleet for which recommendations are provided. The list of 27 vehicles is shown in Figure 1, and the recommended replacements are provided in Table 5.

Across the 27 vehicles for which recommendations are provided, overall EV Suitability scores ranged from a low of 54 to a high of 94 . In about one dozen instances, lower overall scores were a function of low-use vehicles for which insufficient data were provided to be fully confident that a representative sample of the vehicle's driving needs was being assessed. A more telling metric for LDEQ was the Energy Use scores, which averaged 65 and ranged from 23 to 100; importantly only four of the 27 vehicles scored greater than 90 for Energy Use.

The scores illustrate two factors that will have a significant impact on successful integration of EVs into the LDEQ fleet. First, LDEQ vehicles spend a significant amount of time driving at higher speeds, reflecting a lot of highway usage as opposed to urban driving. Second, many of these vehicles regularly drive more miles in a single day than could be supported by one daily charge for an EV. For many of the vehicles in this fleet, access to regular mid-day charging would be necessary to ensure the vehicles would have enough battery power to fulfill their daily driving needs. 


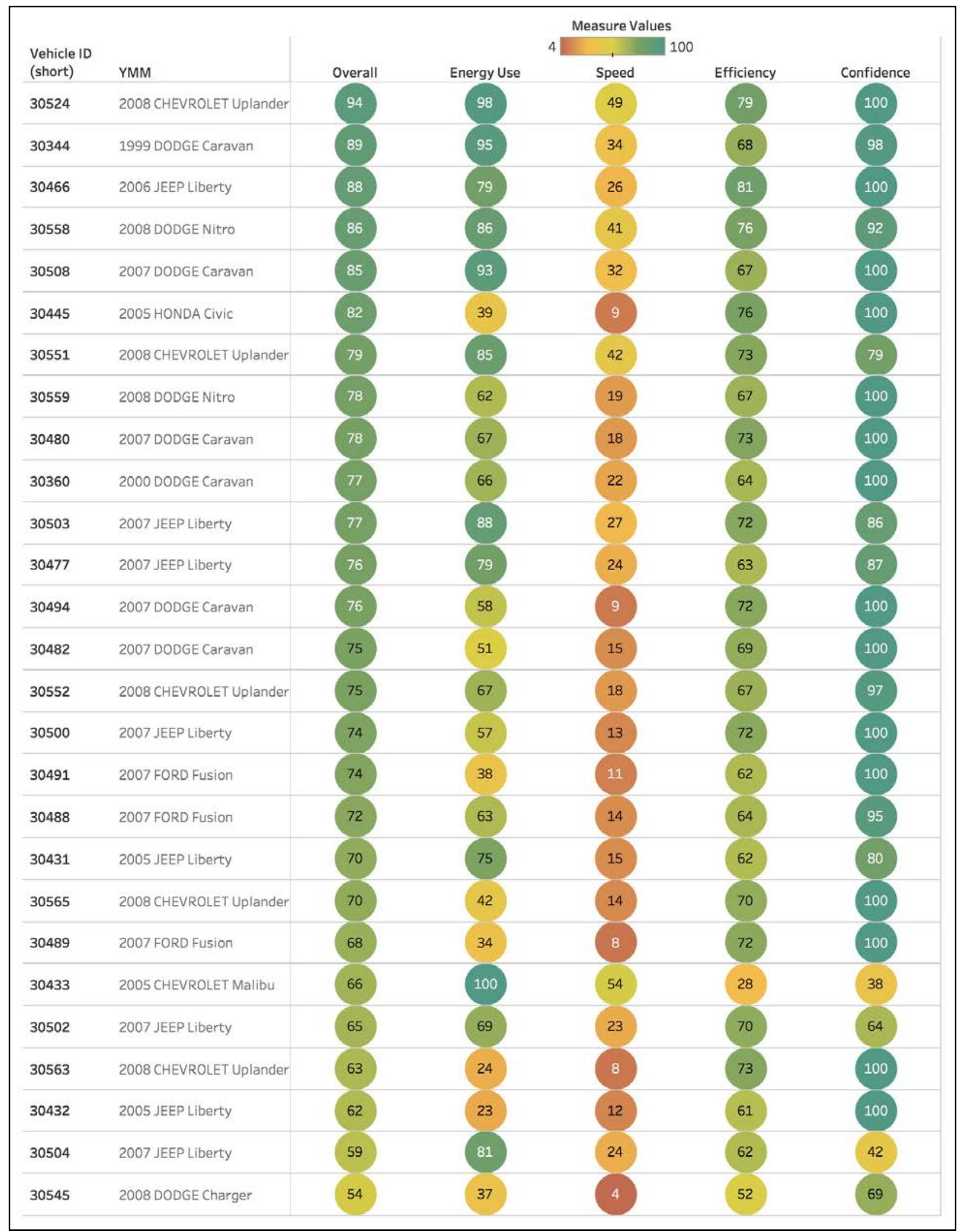

Figure 1. EV Suitability scores by vehicle for LDEQ

This report is available at no cost from the National Renewable Energy Laboratory (NREL) at www.nrel.gov/publications. 
Table 5. LDEQ ezEV Scores and Recommended Replacements

\begin{tabular}{|c|c|c|c|c|c|c|c|c|c|}
\hline Office & Base $^{a}$ & $\begin{array}{l}\text { Vehicle } \\
\text { ID }\end{array}$ & $\begin{array}{l}\text { Vehicle } \\
\text { Type }\end{array}$ & $\begin{array}{l}\text { Vehicle } \\
\text { Year }\end{array}$ & Vehicle Make & Model & $\begin{array}{l}\text { Suitability } \\
\text { Score }\end{array}$ & Recommendation & Assignment \\
\hline \multirow{2}{*}{$\bigcirc$} & $\underline{B R}$ & 30545 & Sedan & 2008 & DODGE & Charger & 47 & ICE & Assigned \\
\hline & NOLA & 30433 & Sedan & 2005 & CHEVROLET & Malibu & 76 & BEV & Assigned \\
\hline \multirow{3}{*}{$\sum_{0}^{\infty}$} & \multirow{3}{*}{$\frac{\alpha}{\infty}$} & 30445 & Sedan & 2005 & HONDA & Civic & 71 & BEV & \multirow{3}{*}{ Pool } \\
\hline & & 30491 & Sedan & 2007 & FORD & Fusion & 60 & PHEV & \\
\hline & & 30489 & Sedan & 2007 & FORD & Fusion & 54 & ICE & \\
\hline \multirow{13}{*}{ 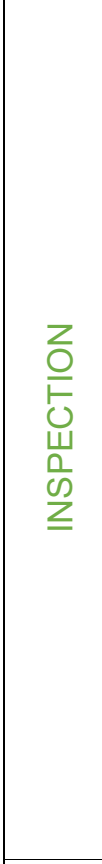 } & \multirow{6}{*}{$\mathrm{BR}$} & 30503 & SUV-sm & 2007 & JEEP & Liberty & 72 & BEV & \multirow{6}{*}{ Shared } \\
\hline & & 30480 & Minivan & 2007 & DODGE & $\begin{array}{l}\text { Grand } \\
\text { Caravan }\end{array}$ & 67 & BEV & \\
\hline & & 30431 & SUV-sm & 2005 & JEEP & Liberty & 65 & PHEV & \\
\hline & & 30552 & Minivan & 2008 & CHEVROLET & Uplander & 65 & PHEV & \\
\hline & & 30488 & Sedan & 2007 & FORD & Fusion & 61 & PHEV & \\
\hline & & 30432 & SUV-sm & 2005 & JEEP & Liberty & 46 & ICE & \\
\hline & \multirow{2}{*}{ LAF } & 30551 & Minivan & 2008 & CHEVROLET & Uplander & 78 & BEV & \multirow{2}{*}{ Shared } \\
\hline & & 30500 & SUV-sm & 2007 & JEEP & Liberty & 62 & PHEV & \\
\hline & \multirow{5}{*}{ NOLA } & 30558 & SUV-sm & 2008 & DODGE & Nitro & 83 & BEV & \multirow{5}{*}{ Shared } \\
\hline & & 30466 & SUV-sm & 2006 & JEEP & Liberty & 81 & PHEV & \\
\hline & & 30477 & SUV-sm & 2007 & JEEP & $\begin{array}{l}\text { Liberty/ } \\
\text { Cherokee }\end{array}$ & 70 & PHEV & \\
\hline & & 30559 & SUV-sm & 2008 & DODGE & Nitro & 67 & BEV & \\
\hline & & 30502 & SUV-sm & 2007 & JEEP & Liberty & 66 & PHEV & \\
\hline \multirow{9}{*}{ 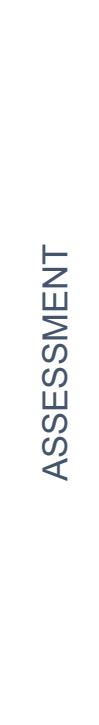 } & \multirow{4}{*}{$\mathrm{BR}$} & 30344 & Minivan & 1999 & DODGE & $\begin{array}{l}\text { Grand } \\
\text { Caravan }\end{array}$ & 83 & BEV & \multirow{2}{*}{ Shared } \\
\hline & & 30494 & Minivan & 2007 & DODGE & $\begin{array}{l}\text { Grand } \\
\text { Caravan }\end{array}$ & 65 & PHEV & \\
\hline & & 30565 & Minivan & 2008 & CHEVROLET & Uplander & 57 & PHEV & \multirow{2}{*}{ Pool } \\
\hline & & 30563 & Minivan & 2008 & CHEVROLET & Uplander & 48 & ICE & \\
\hline & \multirow{3}{*}{$\mathrm{FL}$} & 30524 & Minivan & 2008 & CHEVROLET & Uplander & 90 & PHEV & \multirow{3}{*}{ Shared } \\
\hline & & 30508 & Minivan & 2007 & DODGE & $\begin{array}{l}\text { Grand } \\
\text { Caravan }\end{array}$ & 76 & BEV & \\
\hline & & 30360 & Minivan & 2000 & DODGE & $\begin{array}{l}\text { Grand } \\
\text { Caravan }\end{array}$ & 66 & BEV & \\
\hline & LAF & 30482 & Minivan & 2007 & DODGE & $\begin{array}{l}\text { Grand } \\
\text { Caravan }\end{array}$ & 64 & ICE & Assigned \\
\hline & NOLA & 30504 & SUV-sm & 2007 & JEEP & Liberty & 68 & BEV & Assigned \\
\hline
\end{tabular}

a BR = Downtown Baton Rouge Office; NOLA = New Orleans Office; LAF = Lafayette Office; FL = Department of Agriculture \& Forestry facility on Florida Boulevard in Baton Rouge. 
Long-distance travel among LDEQ vehicles is frequent but varies in terms of when it takes place, and it is not evenly distributed across all vehicles; some travel long distances weekly while others never travel more than 100 miles in a single day. The uneven distribution of long-distance trips presents a challenge for the use of EVs because these trips would use the full battery charge of the vehicle and would also require a mid-day charge to return home. However, they also present an opportunity to (1) reexamine vehicle use and assignment within divisions, and (2) take advantage of publicly available charging infrastructure already deployed across Louisiana.

Nearly every vehicle examined had at least one day in which a BEV would not be suitable for the distance of travel needed for that day. There are only a few pool vehicles that can be checked out by different employees. The other vehicles are assigned to individual employees. We assumed that vehicles were not shared across divisions but could potentially be shared within them.

For these reasons, we propose that LDEQ consider a slight modification to its vehicle assignment practices and implement small car-share pilot programs whereby a small group of EVs deployed into a division would be shared among the employees to whom individual vehicles were previously assigned. These vehicles would not be available to other employees like pool vehicles, but instead would remain exclusive to the assigned drivers. They would, however, be shared by those assigned drivers to ensure that on days on which only short distances are traveled, the BEVs are used, and on longer distance days, the PHEVs are used instead.

There were very few instances in which vehicles within a division have overlapping days with distances greater than 100 miles. However, on days when this did happen-and even on days when it does not - the travel patterns of LDEQ vehicles took them into proximity of existing, publicly accessible EVSE in numerous places around the state. As a result, many long-distance trips could be served by a BEV with some pre-trip planning to stop for an "opportunity charge" that tops off the battery and ensures enough range to complete the trip, similar to adding fuel to the tank of an ICE vehicle. Furthermore, we recommend the installation of Level 2 (L2) EVSE at LDEQ facilities around the state (see Table 6). LDEQ vehicles frequently travel to other LDEQ offices/facilities and could then take advantage of this infrastructure to charge while visiting other offices, particularly for stops longer than 1 hour, which can afford sufficient time to add miles of range for the return trip. This recommendation assumes that infrastructure installed at one LDEQ facility would be available to all vehicles regardless of division assignments.

Knowing that this proposed solution to implement EVs may be a departure from standard operating procedure, it does represent an opportunity to explore a creative solution in a situation in which EVs might otherwise not be a practical solution.

\subsubsection{EVSE Recommendations}

To support the implementation of a successful transition to EVs, LDEQ will need to consider the installation of EVSE or charging stations. A cost-effective EV program deploys an optimal ratio of EV to EVSE based on parking locations, durations, and the time needed to charge vehicles and ensure normal fleet operations. Based on the results above, Table 6 summarizes the recommended EVSE rollout for LDEQ. 
Table 6. High-Volume Parking Locations for LDEQ Vehicles

\begin{tabular}{lll}
\hline Facility & Location & Recommendation \\
\hline \multirow{2}{*}{ Downtown Baton Rouge } & 504 North Street & Two Level 2 chargers \\
& Baton Rouge, LA 70802 & Eight Level 1 chargers \\
New Orleans Office & 201 Evans Road & Two Level 2 chargers \\
& New Orleans, LA 70123 & Five Level 1 chargers \\
Lafayette Office & 111 New Center Drive & One Level 2 charger \\
& Lafayette, LA 70508 & One Level 1 charger \\
Department of Agriculture \& & 5825 Florida Boulevard & One Level 2 chargers \\
Forestry & Baton Rouge, LA 70806 & Two Level 1 charger \\
\hline
\end{tabular}

\subsubsection{LDEQ Lessons Learned}

Two primary lessons were learned from the LDEQ project. The first lesson involved the adaption of the ezEV analytics to fit a third-party source of telematics data. The project was initially proposed for data collection via the Sawatch smartphone app, but the availability of GPS Insight data rendered the need to collect additional data duplicative. The resulting developments demonstrated that available data enable the analytics to be completed for any fleet with existing telematics in a fraction of the time needed to collect data from scratch.

Second, the early version of ezEV analytics overvalued the relative weight of the confidence score. An example is in vehicle 30445 where low energy use (36) and speed scores (9) are overshadowed by the confidence score of 100 in the resulting overall EV Suitability score of 82. Subsequent adjustments to the model would have scored this vehicle below 70 overall and would not recommend the vehicle be replaced with an EV because mid-day charging would be required for an EV to be considered a good fit.

\subsection{Florida Power \& Light}

\subsubsection{Scope of Pilot and Technical Summary}

Data from 17 vehicles were collected during the FPL pilot project's analysis period, June 1 through September 1, 2017, using iPhones FPL issued to individual drivers. ezEV-Fleet was installed on these phones, and the phones remained with individual drivers for the duration of the pilot, during which PTRTelematics captured nearly 2,500 hours of driving activity, 9,300 trips, and 54,000 miles of vehicle telemetry in the monitored FPL vehicles.

During the FPL project, Sawatch monitored the internal consistency of data captured on FPL phones. End points for each trip were compared to determine if and when any trips were missed by a software or hardware failure. Overall, the PTRTelematics software performed better than expected. A 90\% accuracy rate in telemetry capture had been anticipated owing to concerns about extreme temperatures, low battery levels on the phones, hardware failures, and user interference. An initial hardware/software failure of approximately $12 \%$ was observed, a portion of which was a function of short trips falling below the software's capture thresholds (trips less than 3 minutes and/or 0.6 mile). By addressing the threshold size, the failure rate was reduced to approximately $5 \%$. 
We observed two failure modes. In mode one, the phone would fail to recognize it had come into proximity of the vehicle's beacon and would subsequently miss a trip. This can be caused by several things, but the most likely is radio interference in the $2.4-\mathrm{GHz}$ band (this is the unregulated portion of the spectrum and can therefore be noisy) or interference at the phone's Bluetooth antenna caused by other Bluetooth devices attempting to connect at the moment the beacon was encountered. Mode two is a failure by design. In situations where the phone is stressed by user activity, the ezEV app is designed to drop its functionality first. An example of this would be a user attempting web browsing or a voice call when the ezEV app is in the background and the phone battery is below $20 \%$. In cases such as this, it is important the phone's functionality as a communication device is privileged over its functionality as a data capture device.

\subsubsection{Fleet Characteristics}

The 17 vehicles in the pilot were assigned to the Field Service Operations. These vehicles averaged 3,188 miles during the 93-day study data period, which projects to just over 12,500 miles per vehicle annually. These vehicles drive a relatively large number of miles, presenting opportunities and challenges for a transition to EVs. Further, the VMT are not evenly distributed across vehicles, ranging from 85 to 6,706 miles during this period. The number of trips per vehicle ranged from 7 to 1,187 . Average trip lengths ranged from 2.3 miles to 22.2 miles. Table 7 summarizes utilization for each vehicle covered in this analysis.

FPL drivers exhibited a wide range of driving patterns, geographies (representing both large and more compact operational geographies), and frequency of driving. Data collection spanned a large portion of the state of Florida. On the west coast of Florida, the covered territory ranged from Sarasota Springs in the north to Naples in the south. On the east coast of Florida, the covered territory ranged from Palm Valley in the north to the southern portions of the Miami metropolitan area. For most drivers in this study, their routes and/or where they started and stopped for the day were in proximity to existing EVSE charging stations at FPL facilities. ${ }^{9} \mathrm{We}$ note where this was the case for individual drivers in Table 8.

\footnotetext{
${ }^{9}$ EVSE location/availability information is sourced from the U.S. DOE's Alterative Fuel Station Locator: https://www.afdc.energy.gov/. Only over-night charging, and not mid-day charging, was accounted for in this pilot.
} 
Table 7. Individual Vehicle Use Averages, June 1-September 1, 2017

\begin{tabular}{|c|c|c|c|c|c|}
\hline Driver & $\begin{array}{l}\text { Year, Make, } \\
\text { Model }\end{array}$ & Trips & $\begin{array}{l}\text { Avg. } \\
\text { Days in } \\
\text { Operation } \\
\text { (per veh) }\end{array}$ & $\begin{array}{l}\text { Total } \\
\text { VMT }\end{array}$ & $\begin{array}{l}\text { Est. Fuel } \\
\text { Use (gal) }\end{array}$ \\
\hline Driver 1 & 2012 Ford F250 & 577 & 73 & 4,476 & 328 \\
\hline Driver 2 & $\begin{array}{l}2016 \text { Ford } \\
\text { ESCAPE }\end{array}$ & 633 & 59 & 1,605 & 110 \\
\hline Driver 3 & 2013 Ford F150 & 367 & 39 & 2,855 & 270 \\
\hline Driver 4 & 2011 Ford F150 & 1,135 & 54 & 6,345 & 417 \\
\hline Driver 5 & $\begin{array}{l}2016 \text { Ford } \\
\text { ESCAPE }\end{array}$ & 697 & 81 & 6,354 & 265 \\
\hline Driver 6 & $\begin{array}{l}2015 \text { Chevrolet } \\
2500 \mathrm{HD}\end{array}$ & 233 & 21 & 1,808 & 162 \\
\hline Driver 7 & $\begin{array}{l}2015 \text { Chevrolet } \\
1500\end{array}$ & 723 & 50 & 5,488 & 452 \\
\hline Driver 8 & 2004 Ford F150 & 18 & 12 & 85 & 8 \\
\hline Driver 9 & $\begin{array}{l}2017 \text { Ford } \\
\text { ESCAPE }\end{array}$ & 801 & 44 & 1,865 & 113 \\
\hline Driver 10 & $\begin{array}{l}2015 \text { Chevrolet } \\
2500 \mathrm{HD}\end{array}$ & 1,187 & 60 & 4,151 & 402 \\
\hline Driver 11 & 2013 Ford F150 & 375 & 40 & 3,557 & 264 \\
\hline Driver 12 & 2013 Ford F150 & 822 & 75 & 6,706 & 493 \\
\hline Driver 13 & $\begin{array}{l}2017 \text { Ford } \\
\text { ESCAPE }\end{array}$ & 322 & 25 & 833 & 53 \\
\hline Driver 14 & $\begin{array}{l}2015 \text { Chevrolet } \\
1500\end{array}$ & 526 & 33 & 3,722 & 212 \\
\hline Driver 15 & 2012 Ford F250 & 511 & 35 & 2,439 & 248 \\
\hline Driver 16 & 2013 Ford F150 & 7 & 6 & 122 & 5 \\
\hline Driver 17 & $\begin{array}{l}2015 \text { Chevrolet } \\
1500\end{array}$ & 460 & 37 & 1,796 & 195 \\
\hline TOTALS & & 9,394 & 744 & 54,204 & 3,997 \\
\hline
\end{tabular}

\subsubsection{FPL EVSA Results and Recommendations}

The 17 vehicles in the FPL pilot project include a range of different vehicle sizes and types, but the majority of these vehicles are pickup trucks like the Ford F150 and Chevrolet Silverado. FPL indicated interest in the following makes and models of EVs: Chevrolet Bolt BEV, Nissan Leaf BEV, and the Workhorse W15 Pickup PHEV. Accordingly, the ezEV analysis of FPL's fleet used the operational metrics specific to these vehicles as well as the generic BEV. ${ }^{10}$ Of particular

${ }^{10}$ Vehicle specifics: (1) 2017 Chevrolet Bolt BEV (MSRP: $\$ 37,495$; battery capacity: $60 \mathrm{kWh}$; all-electric miles: 238), (2) 2018 Nissan Leaf BEV (MSRP: \$29,990; battery capacity: 40 kWh; all-electric miles: 150), (3) 2019 
interest in this analysis was a comparison of the drive-cycles of these vehicles as opposed to whether a smaller sedan EV could actually replace a truck operating in these roles. At the time of this analysis, Sawatch was unable to account for things like passenger/cargo carrying or towing needs for the purpose of suggesting whether or not the larger vehicles were needed for those capabilities.

Overall EV Suitability scores for FPL range from a low of 46 to a high of 86, as shown in Figure 2. There were only two instances for which an insufficient amount of data was collected, which is reflected in the low Confidence scores. Energy Use scores also vary widely for FPL vehicles, averaging 65 and ranging from 15 to 100; importantly only seven of 17 vehicles scored greater than 90 for Energy Use. In the same way the state agency vehicles in Louisiana exhibited a noticeable number of days with long distance travel, so did the FPL vehicles. The main difference is that FPL vehicles' high mileage took place within more compact geographies, reflecting the "service territory" nature of their operations.

The combination of these scores and the higher average speed scores (37) versus LDEQ's (22) and the relatively compact operational geography of FPL vehicles presents interesting opportunities for integration of EVs into the FPL fleet. Importantly, more frequent driving at higher speeds can have an adverse impact on EV range in some instances and the FPL vehicles spend a lot of time on rural highways at higher speeds. As a result, many of these vehicles would also need access to midday charging to complete their daily drive cycles and, because they tend to operate in a consistent and known territory, regular access to midday charging could be more easily facilitated. This is the opposite of LDEQ's operations, which have sporadic long-distance trips to many different locations where access to EVSE would be less common and/or unknown to drivers in an unfamiliar location.

For these reasons, the service territory operational model presents attractive opportunities for EV adoption. FPL has the right combination of high-mileage vehicles and compact operational geography that could facilitate more frequent access to charging during operational hours. This possibility is further enhanced by past FPL investments in EVSE (See Table 8) at the facilities where these vehicles are frequently garaged overnight.

Workhorse W15 PHEV (MSRP: \$52,500; battery capacity: $50 \mathrm{kWh}$; all-electric miles: 80), and (4) generic BEV (MSRP: \$33,806; battery capacity: $27 \mathrm{kWh}$; all-electric miles: 102). 


\begin{tabular}{|c|c|c|c|c|c|c|}
\hline \multirow[b]{3}{*}{ Driver } & \multirow[b]{3}{*}{ YMM } & \multicolumn{5}{|c|}{ Measure Values } \\
\hline & & & & & 00 & \\
\hline & & Overall & Energy Use & Speed & Efficiency & Confidence \\
\hline Driver 1 & 2012 Ford F250 & 59 & 66 & 19 & 64 & \\
\hline Driver 2 & 2016 Ford ESCAPE & & & 47 & & \\
\hline Driver 3 & 2013 Ford F150 & 7 & & 40 & & \\
\hline Driver 4 & 2011 Ford F150 & 48 & & 25 & & \\
\hline Driver 5 & 2016 Ford ESCAPE & 46 & 40 & 15 & & \\
\hline Driver 6 & 2015 Chevrolet 2500HD & 68 & 6 & 40 & & \\
\hline Driver 7 & 2015 Chevrolet 1500 & 57 & 47 & 32 & & \\
\hline Driver 8 & 2004 Ford F150 & & & 75 & & \\
\hline Driver 9 & 2017 Ford ESCAPE & & & 36 & & \\
\hline Driver 10 & 2015 Chevrolet $2500 \mathrm{HD}$ & 6 & & 52 & & \\
\hline Driver 11 & 2013 Ford F150 & & 64 & 32 & & \\
\hline Driver 12 & 2013 Ford F150 & 49 & 34 & 26 & & \\
\hline Driver 13 & 2017 Ford ESCAPE & 86 & 100 & 51 & & \\
\hline Driver 14 & 2015 Chevrolet 1500 & 52 & 45 & 28 & & \\
\hline Driver 15 & 2012 Ford F250 & & 9 & 39 & & \\
\hline Driver 16 & 2013 Ford F150 & 63 & 100 & 27 & & \\
\hline Driver 17 & 2015 Chevrolet 1500 & 02 & 04 & 44 & & \\
\hline
\end{tabular}

Figure 2. EV Suitability scores by vehicle for FPL

\subsubsection{EVSE Recommendations}

To some extent, FPL already has enough EVSE in place to support the successful transition to EVs among the vehicles and duty cycles observed. Only six of the FPL vehicles park overnight at locations that do not already have existing charging infrastructure. Two of those are at residential locations, and the other four are at existing FPL facilities in Venice, Punta Gorda, and Sarasota that did not yet have chargers. Table 8 summarizes the recommended EVSE rollout, as well as existing EVSE for FPL vehicles in this pilot project. 
Table 8. EV and EVSE Recommendations for FPL Vehicles

\begin{tabular}{|c|c|c|c|}
\hline Driver & Year, Make, Model & $\begin{array}{l}\text { Recommended } \\
\text { Replacement }\end{array}$ & Existing and Needed EVSE \\
\hline Driver 1 & 2012 Ford F250 & Chevrolet Bolt & $\begin{array}{l}\text { HAS EVSE: Toledo Blade Service } \\
\text { Center }\end{array}$ \\
\hline Driver 2 & 2016 Ford ESCAPE & $\begin{array}{l}2017 \text { Nissan Leaf } \\
\text { or Ford Focus }\end{array}$ & $\begin{array}{l}\text { HAS EVSE: Perrine Service } \\
\text { Center }\end{array}$ \\
\hline Driver 3 & 2013 Ford F150 & 2018 Nissan Leaf & $\begin{array}{l}\text { NEEDS EVSE: Residential, Stuart, } \\
\text { FL } 34997\end{array}$ \\
\hline Driver 4 & 2011 Ford F150 & Chevrolet Bolt & $\begin{array}{l}\text { HAS EVSE: Ft. Meyers Service } \\
\text { Center }\end{array}$ \\
\hline Driver 5 & 2016 Ford ESCAPE & $\begin{array}{l}\text { Chevrolet Bolt or } \\
\text { PHEV }\end{array}$ & $\begin{array}{l}\text { NEEDS EVSE: Residential, Palm } \\
\text { Coast } 32137\end{array}$ \\
\hline Driver 6 & $\begin{array}{l}2015 \text { Chevrolet } \\
2500 \mathrm{HD}\end{array}$ & 2018 Nissan Leaf & $\begin{array}{l}\text { HAS EVSE: Ft. Meyers Service } \\
\text { Center }\end{array}$ \\
\hline Driver 7 & $\begin{array}{l}2015 \text { Chevrolet } \\
1500\end{array}$ & $\begin{array}{l}\text { Chevrolet Bolt or } \\
\text { PHEV }\end{array}$ & $\begin{array}{l}\text { NEEDS EVSE: FPL facility at } 620 \\
\text { Albee Farm Road, Venice } 34285\end{array}$ \\
\hline Driver 8 & 2004 Ford F150 & Not enough data. & $\mathrm{n} / \mathrm{a}$ \\
\hline Driver 9 & 2017 Ford ESCAPE & $\begin{array}{l}2017 \text { Nissan Leaf } \\
\text { or Ford Focus }\end{array}$ & $\begin{array}{l}\text { HAS EVSE: Boynton Beach } \\
\text { Service Center }\end{array}$ \\
\hline Driver 10 & $\begin{array}{l}2015 \text { Chevrolet } \\
2500 \mathrm{HD}\end{array}$ & 2018 Nissan Leaf & $\begin{array}{l}\text { NEEDS EVSE: FPL facility at } 2344 \\
\text { 12th Street, Sarasota } 34237\end{array}$ \\
\hline Driver 11 & 2013 Ford F150 & $\begin{array}{l}\text { Chevrolet Bolt or } \\
\text { PHEV }\end{array}$ & $\begin{array}{l}\text { HAS EVSE: St. Lucie Service } \\
\text { Center }\end{array}$ \\
\hline Driver 12 & 2013 Ford F150 & Chevrolet Bolt & $\begin{array}{l}\text { NEEDS EVSE: FPL facility at } 122 \\
\text { E. Charlotte Ave, Punta Gorda } \\
33950\end{array}$ \\
\hline Driver 13 & 2017 Ford ESCAPE & $\begin{array}{l}2017 \text { Nissan Leaf } \\
\text { or Ford Focus }\end{array}$ & $\begin{array}{l}\text { HAS EVSE: South Dade Service } \\
\text { Center }\end{array}$ \\
\hline Driver 14 & $\begin{array}{l}2015 \text { Chevrolet } \\
1500\end{array}$ & Chevrolet Bolt & $\begin{array}{l}\text { NEEDS EVSE: FPL facility at } 122 \\
\text { E. Charlotte Ave, Punta Gorda } \\
33950\end{array}$ \\
\hline Driver 15 & 2012 Ford F250 & $\begin{array}{l}2017 \text { Nissan Leaf } \\
\text { or Ford Focus }\end{array}$ & $\begin{array}{l}\text { HAS EVSE: Perrine Service } \\
\text { Center }\end{array}$ \\
\hline Driver 16 & 2013 Ford F150 & Not enough data. & $\mathrm{n} / \mathrm{a}$ \\
\hline Driver 17 & $\begin{array}{l}2015 \text { Chevrolet } \\
1500\end{array}$ & 2018 Nissan Leaf & $\begin{array}{l}\text { HAS EVSE: Richmond Service } \\
\text { Center }\end{array}$ \\
\hline
\end{tabular}

\subsubsection{FPL Lessons Learned}

Two primary lessons were learned from the FPL project. First, data collection using the iPhone assigned to an individual as part of his or her job function performed better than expected. It likely also helped that the Sawatch team attempted to limit the negative impacts of the human element on data gathering by visiting and briefing the FPL drivers on the project, the objectives, and the technical aspects of the project. With this knowledge, the drivers installed the app on 
their phones, turned Bluetooth on, and placed a beacon in the vehicles. We asked them to simply leave things alone, untouched. Fifteen drivers followed these steps, and data collection ensued largely uninterrupted; four drivers did not, which is reflected in the two low confidence scores; and two whose data collection was never initiated at all and which are therefore not included in the 17 vehicles noted in this report.

Second, the operational characteristics and individual vehicle duty cycles of a service territory fleet are particularly well suited for EVs where other specialized needs are also absent (e.g., cargo carrying capacity, towing needs, harsh terrain). Because FPL is a utility electricity provider with prior investments in charging at its own facilities, the combination of other attributes aligns well for EVs: compact operation geography, high-mileage vehicles, recurring overnight parking locations, and less time spent traveling at interstate speeds.

\subsection{University of Connecticut}

\subsubsection{Scope of Pilot Project and Technical Summary}

UConn had five vehicles participate in the pilot project. ${ }^{11}$ Data were collected from March 7 through May 23, 2017. Because UConn did not uniformly issue phones to employees and many of the drivers were part-time employees and students, it was not possible to have phones assigned to, and remain with, drivers. As such, UConn purchased its own iPhones-Apple SE models - with minimal data plans to leave in each vehicle and collect data. These phones remained in each vehicle over the duration of data capture and were plugged into a power source. During the pilot period, PTRTelematics captured more than 500 hours of driving activity, 1,500 trips, and 5,600 miles of vehicle telemetry in the monitored UConn vehicles. During the same period, it detected 422 hard-braking events and 448 hard-acceleration events.

The software performed very well in terms of data capture. About $97 \%$ of all trips and miles were captured. The most consistent point of data-capture failure was a recurring duty cycle from the UConn campus to the Hartford airport. On these cycles, the trip to the airport was consistently recorded, but the corresponding return trip of approximately 23 miles was missed. Most missed miles identified in this analysis are explained by the return trip from the airport. Because there were numerous instances in which the return trip from the airport was recorded, and hence the impact that travel has on estimated energy use is known, these miles were not added back into the analysis. ${ }^{12}$ During these failure events, the vehicle either idled or sat with the ignition turned to the accessory-on position; possibly the driver was listening to the radio while waiting for passengers to arrive on incoming flights. After 6 minutes of idling or accessory use without significant movement, the ezEV software turned itself off. Because the software went into an off state but the vehicle was running or at least powering the Bluetooth beacon, the software did not recognize the return to campus from the airport as a new trip-instead staying in the off state for the entire return trip. An update to the software has corrected this issue for future

\footnotetext{
${ }^{11}$ The UConn pilot project has been documented in a previous standalone publication (https://www.nrel.gov/docs/fy18osti/69018.pdf). The summary here is purposefully condensed.

${ }^{12}$ Roundtrip travel from UConn to the airport is roughly 70 miles depending on the route taken. These missed trips were not added back into the analysis because the impact of this frequent trip is known; the full roundtrip drive could be completed with the generic BEV but would exhaust the battery of a PHEV in every instance.
} 
use. Documenting this issue also served as an opportunity to educate drivers about the negative issues associated with excessive idling while awaiting ride-pickups at the airport.

A $0 \%$ hardware failure rate and a software failure rate of about $3 \%$ were observed. With the software issue addressed, a software capture rate of about $98 \%$ is anticipated in the future. Two other failure modes were encountered: phones would shut down during long periods of cold weather (e.g., winter nights) and phones would be unplugged from the power source or removed from the vehicles (and typically then turned in to lost and found). These were uncommon and did not have a significant impact on data collection but are nonetheless noteworthy for purposes of documenting the pros and cons of smartphone-based telematics.

\subsubsection{Fleet Characteristics}

Vehicles participating in the pilot were assigned to the Parking and Transportation Services Department. These vehicles averaged 1,129 miles each during the 77-day study data period, which projects to just under 3,400 miles per vehicle annually, accounting for use in an academic campus environment and subject to school vacations and periods of less activity. These vehicles drive relatively few miles compared with vehicles in other public-sector fleets, presenting opportunities and challenges for a transition to EVs. Further, the VMT are not evenly distributed across vehicles, ranging from 673 to 2,067 miles during this period. Trips per vehicle ranged from 198 to 533. Table 9 shows the use summary for each vehicle covered in this analysis.

This use pattern (high number of trips relative to low total mileage) reflects vehicles that operate frequently within the small geographic area of the UConn campus. Three of the five vehicles traveled exclusively on campus during the data-collection period (9-527, 9-528, 9-154), while the other two had multiple days of off-campus travel: 9-095 (9 days off campus) and 9-153 (11 days off campus). In total, $90 \%$ of all data collected on the five vehicles was from activity occurring within 1.5 miles of the campus center, reflecting geographically centralized operations. When traveling on campus, the vehicles averaged just 9 miles per hour (MPH), with speeds rarely exceeding $35 \mathrm{MPH}$. In contrast, the long-distance trips off campus averaged $40 \mathrm{MPH}$, with large portions spent at highway speeds of 55-75 MPH. Average trip lengths were about 3 miles on campus and 40 miles off campus. 
Table 9. UConn Individual Vehicle Use Averages, June 1-September 1, 2017

\begin{tabular}{llllll}
\hline Driver & Year, Make, Model & Trips & $\begin{array}{l}\text { Avg. } \\
\text { Days in } \\
\text { Operation } \\
\text { (per veh) }\end{array}$ & $\begin{array}{l}\text { Total } \\
\text { VMT }\end{array}$ & $\begin{array}{l}\text { Est. Fuel } \\
\text { Use (gal) }\end{array}$ \\
\hline $9-095$ & $\begin{array}{l}\text { 2012 Dodge Grand } \\
\text { Caravan }\end{array}$ & 198 & 30 & 673 & 72 \\
$9-153$ & $\begin{array}{l}\text { 2013 Dodge Grand } \\
\text { Caravan }\end{array}$ & 228 & 43 & 1,181 & 82 \\
$9-154$ & $\begin{array}{l}\text { 2012 Dodge Grand } \\
\text { Caravan }\end{array}$ & 202 & 28 & 792 & 99 \\
$9-527$ & $\begin{array}{l}\text { 2015 Dodge Grand } \\
\text { Caravan }\end{array}$ & 346 & 46 & 933 & 121 \\
\hline $9-528$ & $\begin{array}{l}\text { 2015 Dodge Grand } \\
\text { Caravan }\end{array}$ & 533 & 52 & 2,067 & 251 \\
\hline TOTALS & & 5,647 & 199 & 1,507 & 625 \\
\hline
\end{tabular}

\subsubsection{UConn EVSA Results and Recommendations}

The five study vehicles were Dodge Caravan minivans, largely used to transport students around campus and to and from a few locations throughout the state, such as Bradley International Airport (BDL) and downtown Hartford. Owing to the frequency of local, low-mileage travel, these vehicles' drive cycles fit very well with EV capabilities. However, given the need to carry several passengers and sometimes travel longer distances, UConn requested that comparisons be made with several specific PHEVs: the Ford C-Max Energi, Ford Fusion Energi, and Chrysler Pacifica. In addition, the Ford Focus BEV is included in the analysis. ${ }^{13}$ This was the first pilot project for which make and model-specific scoring on the ezEV platform was provided. The results are presented in Table 10. Despite significant differences in terms of the number of trips and miles recorded per vehicle, all three of these vehicles exhibit remarkably similar EV suitability profiles.

These vehicles also experienced a significant amount of low-speed travel with numerous starts, stops, and idling events. These driving patterns suit EVs well, but they are inefficient for ICE vehicles because, for example, an ICE vehicle's miles per gallon is zero when idling. Idling in UConn vehicles while on campus consumed more than 100 gallons of gasoline in the 77-day data collection - almost $17 \%$ of total fuel use. Operating on electricity would eliminate this fuel consumption almost entirely, because EVs use a negligible amount of battery power when idling. ${ }^{14}$

\footnotetext{
${ }^{13}$ Electric vehicle specifics used for suitability assessment: 1) Generic BEV (MSRP: \$33,806; battery size: $27 \mathrm{kWh}$; electric range: 102 miles), 2) Ford Focus BEV (MSRP: \$29,170; battery size: $23 \mathrm{kWh}$; electric range: 76 miles), 3) Ford Fusion PHEV (MSRP: \$33,120; battery size: $7.6 \mathrm{kWh}$; electric range: 20 miles; gasoline range: 500+ miles), 4) Ford C-Max Energi PHEV (MSRP: \$27,120; battery size: $7.6 \mathrm{kWh}$; electric range: 20 miles; gasoline range: 500+ miles), and 5) Chrysler Pacifica PHEV (MSRP: \$41,995; battery size: $16 \mathrm{kWh}$; electric range: 33 miles; gasoline range: $500+$ miles).

${ }^{14}$ The electricity used while idling will increase if auxiliary systems — such as the audio/stereo, heater, and air conditioning - are used.
} 
The two UConn vehicles with consistent off-campus travel show different EV Suitability scores overall, especially for the PHEV models of interest to UConn (vehicles 9-095 and 9-153). When they travel exclusively on campus over the course of a day, they exhibit nearly identical behavior, travel patterns, and metrics to the three vehicles discussed above. Accordingly, transition to electric miles is recommended for that portion of their driving needs. However, the longer-distance trips that take place on about $27 \%$ of all travel days will have a noticeable impact on the ability to transition all miles to electricity.

Table 10. Differences in Energy Use and Overall EV Suitability Scores across Select EVs

\begin{tabular}{lllllll}
\hline Make and Model & Score by Vehicle & $\mathbf{9 - 0 9 5}$ & $\mathbf{9 - 1 5 3}$ & $\mathbf{9 - 1 5 4}$ & $\mathbf{9 - 5 2 7}$ & $\mathbf{9 - 5 2 8}$ \\
\hline \multirow{2}{*}{ Generic BEV } & Energy Use & 94.7 & 93.5 & 100 & 100 & 100 \\
& Overall & 96.1 & 92.3 & 98.4 & 98.4 & 98.3 \\
\hline \multirow{2}{*}{ Ford Focus BEV } & Energy Use & 90.0 & 90.4 & 100 & 100 & 100 \\
& Overall & 93.8 & 91.4 & 98.4 & 98.4 & 98.3 \\
\hline \multirow{2}{*}{ Chrysler Pacifica PHEV } & Energy Use & 90.0 & 76.4 & 100 & 100 & 98.1 \\
& Overall & 93.1 & 87.5 & 98.4 & 98.4 & 97.5 \\
Ford Fusion Energi & Energy Use & 76.7 & 64.5 & 78.8 & 84.4 & 60.6 \\
PHEV & Overall & 88.1 & 81.4 & 90.9 & 93.7 & 82.6 \\
\hline Ford C-Max Energi & Energy Use & 76.7 & 64.5 & 78.8 & 84.4 & 60.6 \\
PHEV & Overall & 88.1 & 81.4 & 90.9 & 93.7 & 82.6 \\
\hline
\end{tabular}

\subsubsection{EVSE Recommendations}

All five of the vehicles tracked in this analysis regularly ended their days in the parking lots surrounding the Parking Services building at UConn, where there already is one L2 EVSE port. Although they did not often stop at the North Garage or South Garage on campus, each of those buildings also has two L2 EVSE units that UConn fleet vehicles could use. Figure 3 shows trip ending locations on campus for each study vehicle.

Given the frequency of trips and days that end with a vehicle parking in the lot just northwest of the Parking Services building, UConn should consider adding at least one more L2 EVSE unit to the charging station in that lot. This unit would help support the charging needs of the three vehicles that operated exclusively on campus during this study, if those vehicles were replaced with EVs. Although the Parking Services building offers the most frequent and immediate opportunities to use and expand EVSE on the UConn campus, the five study vehicles also had sporadic trips that stopped or started near the North and South Garages, each of which has two Level 2 EVSE units. Any EVs deployed into the UConn fleet should have access to this infrastructure when necessary, especially prior to the deployment of any additional EVSE. 


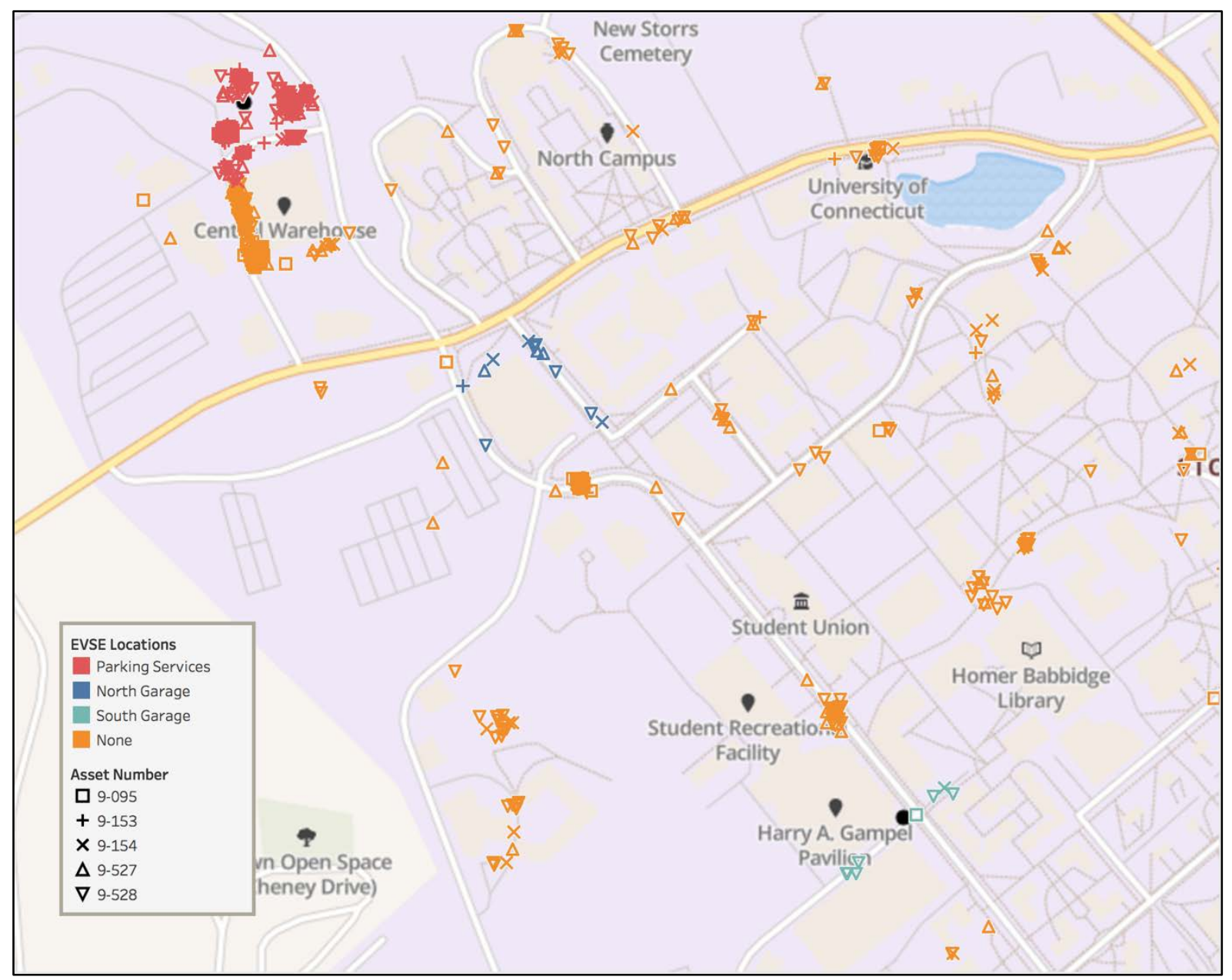

Figure 3. Vehicle trip ending locations relative to existing EVSE on UConn campus

\subsubsection{UConn Lessons Learned}

There were a number of valuable lessons learned from the UConn project. While the process of leaving phones in individual vehicles performed well in terms of data capture, it does not really represent a departure from traditional telematics where hardware is purchased and installed on the vehicles. In these scenarios, added value of reliable data capture from a traditional telematics device may enhance the utility gained versus the potential for interruption to data collection on a phone, even if the latter is accomplished at a lower cost.

Second, the UConn project proved the value of having make and model-specific scoring on the ezEV platform so that decision makers can see the relative impact of choosing one particular vehicle versus another in terms of energy use and economics, among other factors. This request from UConn led to subsequent enhancements to the ezEV analytics package that automates the recommendation of specific makes and models to fit specific use cases/vehicle types.

Third, campus environments present an attractive use case for EVs but nonetheless some challenges as well. Small geography and high use in terms of hours in service, as opposed to high mileage, combined with high rates of idling equate to an ideal use of an electric drivetrain. The UConn example presents two complicating factors: (1) infrequent, but still necessary, long- 
distance travel may nevertheless require the use of ICE vehicles, and (2) lower overall mileage may prevent a good economic case for EVs in terms of achieving an overall lifetime savings from operating vehicles on electricity (the more miles an EV drives, the faster the return on investment). This latter question opens additional opportunities for study comparing the ability of universities and other public-sector entities to procure EVs below MSRP. Where they are able to procure vehicles from pre-negotiated contracts, access grants, and/or monetize tax credits and rebates through leasing, the payback period for satisfactory return on investment is reduced.

\subsection{State of Rhode Island}

\subsubsection{Scope of Pilot and Technical Summary}

Three departments within the State of Rhode Island's fleet participated in the analysis: Department of Transportation (DOT), Department of Environmental Management, and the University of Rhode Island (URI). Data were collected from October 17 through December 20, 2017. Driver phones were not available for most of the vehicles tracked and, as a result, 20 Sawatch-owned phones and two state-issued iPhones were equipped with the ezEV-Fleet application and placed in the vehicles included in this pilot. There were 22 total vehicles included as part of the original pilot analysis, but reliable data were only collected for a handful of the vehicles.

Sawatch procured inexpensive LG Rebel LTE phones and correspondingly inexpensive dataonly cell plans. The LG Rebel phone was selected after testing three phones running the Android platform, including a more expensive LG model and a less expensive Huawei model. The more expensive LG model was cost prohibitive for the project, and the Huawei model's GPS implementation was highly unreliable. The selected LG model ran Android version 5.1.1, had a 1.1-GHz processor, and has fairly accurate GPS and accelerometer implementations.

During testing of the PTRTelematics framework on the LG devices, trip identification procedures that were determined to work reliably on iOS, Samsung, and Pixel smartphones were found to be unreliable on the lower-end LG Rebels. To compensate for the lack of stand-alone trip detection, customized Android and server-side software were developed for this project. The software was designed to wake the phone at 15-minute intervals and report its location and movement to the Sawatch API. On the server side, multiple methods were written to model the received telemetry into trip-level data, on which Sawatch's ezEV algorithms would be run. The approach was designed to allow ezEV to capture the context and daily geography of the vehicles in the project.

The 20 phones were deployed into the vehicles with the charging cords attached, and a dual port USB charger was connected to each vehicle's DC accessory port. The phones were placed in such a way as to make them inconspicuous and yet still connected to the vehicle DC accessory ports for charging.

While this approach eliminated the need for a beacon, it posed a problem from the standpoint of the phone's data collection cycles. Without entering and exiting a beacon's range, the phones would need to rely on accelerometer data for trip start and stop recognition. Sawatch determined that, though this would work in some cases, it might be unreliable in others because the phones would power down their accelerometers if left idle for a few hours. Sawatch's solution to address 
this issue was to have the phones report geospatial data to Sawatch's servers every 15 minutes, and the resulting information would be modeled into vehicle telemetry at a trip level of detail.

After placing the 20 LG phones into the vehicles, telemetry was received back from 17 of those phones; this was largely in line with expectations. Telemetry was also received from the two state-issued iPhones. Of the 17 LG phones, seven began failing within the first two weeks of data collection. This failure rate was higher than expected, but similar results have been experienced in subsequent experiments in which phones were placed in motor pool vehicles. There are multiple reasons for such failures, but they typically result from driver behavior or cold weather. Phones are often unplugged from the DC port so that the driver can use the port for other purposes. In other instances, phones placed in the vehicles with the intention that they stay with the vehicles are instead removed and delivered to lost and found. In addition, charging cords have become dislodged or repurposed. Cold weather has also been found to cause phone batteries to deplete more rapidly, thereby disabling the phones. The cold weather issue became especially prominent in December as the phones began powering down in the lower temperatures. In this project, it appeared that the handset's battery voltage fell below required thresholds when overnight temperatures fell below 30 degrees.

In parallel with the location reporting approach, Sawatch installed its standard ezEV-Fleet telematics application on the phones. Due to the deficiencies with inexpensive phone hardware and the external issues noted above, this approach produced mixed results. In many cases, the selected phone's accelerometers were not consistently able to cycle the phones into data capture modes due to the issues noted above.

Overall, the results of the 15-minute telemetry reporting approach were mixed, and the reliability of the handsets and the modeling algorithms failed to achieve what would be considered "ground truth" data. In some cases, this method produced wild or improbable results where vehicles were seen to move several hundred miles a day and for many days in a row. While it is possible to see this kind of range from fleet vehicles, it seems unlikely in this case considering the vehicle use cases and Rhode Island's small geographic footprint. It seems more likely this was caused by the lower-quality hardware (i.e., phones) employed for this pilot project and the resulting inaccuracies in the analytic methods result from the corresponding gaps in data collection.

The deficiencies stemming from the noted LG phones, however, stand in stark contrast to the results achieved in the two instances Rhode Island drivers volunteered to use their iPhones with the standard ezEV-Fleet-Bluetooth beacon approach. For those two phones, the telemetry was consistent and accurate.

Sufficient data were not collected for many vehicles due to the issues described above. Usable results were not generated for the Department of Environmental Management vehicles. The DOT vehicles had good results for the two iPhones, but confidence in the ezEV recommendations for the remaining four vehicles is limited due to small sample sizes of data. Seven URI vehicles collected usable data on the Android platform; however, only three of those vehicles collected sample sizes large enough to generate sufficient confidence in the associated recommendations. The remaining four vehicles did not have sufficient sample sizes to produce recommendations with confidence. Table 11 summarizes the data collection by vehicle. 
Table 11. Summary of Data Averages Collected from October 17-December 20, 2017

\begin{tabular}{|c|c|c|c|}
\hline Data Collection Status & $\begin{array}{l}\text { Plate } \\
\text { Number }\end{array}$ & $\begin{array}{l}\text { Days of } \\
\text { Use }\end{array}$ & $\begin{array}{l}\text { VMT } \\
\text { Total }\end{array}$ \\
\hline \multirow{2}{*}{ Good Data (iPhone) } & 2636 & 12 & 324 \\
\hline & 2626 & 34 & 944 \\
\hline \multirow{12}{*}{ Usable Data (Android) } & 1933 & 22 & 1,874 \\
\hline & 1286 & 18 & 1,756 \\
\hline & 717932 & 18 & 1,434 \\
\hline & 1940 & 5 & 1,004 \\
\hline & 2596 & 3 & 470 \\
\hline & 2084 & 11 & 438 \\
\hline & 1896 & 2 & 431 \\
\hline & 2245 & 3 & 391 \\
\hline & 838 & 9 & 270 \\
\hline & 1678 & 3 & 233 \\
\hline & 8 & 3 & 217 \\
\hline & 1909 & 1 & 147 \\
\hline \multirow{6}{*}{ No Usable Data (Android) } & 45 & $\mathrm{n} / \mathrm{a}$ & $\mathrm{n} / \mathrm{a}$ \\
\hline & 2468 & $\mathrm{n} / \mathrm{a}$ & $\mathrm{n} / \mathrm{a}$ \\
\hline & 827 & $\mathrm{n} / \mathrm{a}$ & $\mathrm{n} / \mathrm{a}$ \\
\hline & 1011 & $\mathrm{n} / \mathrm{a}$ & $\mathrm{n} / \mathrm{a}$ \\
\hline & 1052 & $\mathrm{n} / \mathrm{a}$ & $\mathrm{n} / \mathrm{a}$ \\
\hline & 2531 & $\mathrm{n} / \mathrm{a}$ & $\mathrm{n} / \mathrm{a}$ \\
\hline \multirow{2}{*}{$\begin{array}{l}\text { Bad Data - Removed from } \\
\text { Analysis (Android) }\end{array}$} & 1662 & $\mathrm{n} / \mathrm{a}$ & $\mathrm{n} / \mathrm{a}$ \\
\hline & 1583 & $\mathrm{n} / \mathrm{a}$ & $\mathrm{n} / \mathrm{a}$ \\
\hline TOTALS & 1,206 & 148 & 9,931 \\
\hline
\end{tabular}

Despite the data collection issues, some useful conclusions may be drawn from the analyses.

\subsubsection{Fleet Characteristics}

Two vehicles assigned to individual employees within the DOT fleet had the ezEV-Fleet app installed on state-issued iPhones. Twelve vehicles recorded usable data on the Android platform; however, most of them did not record enough data to make an informed decision as to whether or not the vehicle ought to be replaced with an EV. Six vehicles did not record enough reliable data to be used in this analysis, and data from two vehicles were not high-quality enough to be used for analysis.

As a result of the data collection challenges, it was not possible to generate usable results for the Department of Environmental Management vehicles. The DOT vehicles had good results for the two iPhones, but confidence in the ezEV recommendations for the remaining four vehicles is 
limited due to small sample sizes of data. Seven URI vehicles collected usable data on the Android platform; however, only three of those vehicles collected sample sizes large enough to generate sufficient confidence in the associated recommendations. The remaining four vehicles did not have sufficient samples sizes to produce recommendations with confidence.

\subsubsection{Rhode Island EVSA Results and Recommendations}

Where data collection was sufficient to make a confident recommendation, the URI vehicles appear to be very good candidates for conversion to EVs based on utilization rates that fit the technology as well as a relatively small geographic footprint that the vehicles covered. Comprehensive results for all vehicles are available online. The two DOT vehicles with sufficient data would both perform very well as BEVs.

The three URI vehicles with enough data to make an informed recommendation all show more VMT than do the DOT vehicles. As such, the recommended vehicles include a Nissan Leaf and two PHEVs. While the geographic footprint where these vehicles are operated is also relatively small, concentrated around the URI campus, they averaged about 90 miles per day of driving. However, all three vehicles had multiple days on which their driving would have exceeded the battery capacity of the Ford Focus, Nissan Leaf, or Chevrolet Bolt. Given this sporadic high utilization, a PHEV like the Chevrolet Volt or Ford Fusion would be a good option. On lower utilization days the vehicle could still cover the majority of its miles on electricity while the backup gasoline engine would be available to provide needed longer range on higher utilization days.

An alternative scenario could be to put one of the larger battery BEVs into these applications; if this is done, it is recommended that particular focus be provided to closely manage any needs for midday charging. Either a Nissan Leaf or Chevrolet Bolt could function very well in these applications, provided there is ready access to midday charging on campus. It is believed that local EVSE would always be in proximity given the small footprint of where the vehicles travel. At the very least, these vehicles would need access to a Level 2 charger and could potentially benefit from a DC fast charger to support the days with longer operational hours. Across these three vehicles, there were only eight days (14\%) on which URI would need to manage the higher mileage use cases.

\subsubsection{EVSE Recommendations}

Recommendations are noted in Table 12 and reflect where reliable data were collected.

Table 12. EV and EVSE Recommendations for Rhode Island Vehicles

\begin{tabular}{llll}
\hline Vehicle ID & Department & $\begin{array}{l}\text { EV } \\
\text { Recommendations }\end{array}$ & Infrastructure Needs \\
\hline 2636 & RI DOT & Ford Focus BEV & DOT Parking Garage \\
2626 & RI DOT & Ford Focus BEV & DOT Parking Garage \\
717932 & URI & Nissan Leaf & URI Motor Pool \\
1286 & URI & PHEV & URI Motor Pool \\
1933 & URI & PHEV & URI Motor Pool \\
\hline
\end{tabular}




\subsubsection{Rhode Island Lessons Learned}

The primary lesson learned from the Rhode Island project is that data collection is not trivial and the various means to collect data are not created equal. Going into this project, Sawatch hoped to validate the performance of a very low-cost telematics data collection method. The low-cost smartphones used for data collection in the Rhode Island pilot did not generate the desired quality of data, and therefore the Sawatch analytics could not perform as hoped for this portion of the project.

\subsection{State of Colorado}

\subsubsection{Scope of Pilot and Technical Summary}

The State of Colorado installed the ezEV smartphone application in 18 fleet vehicles from August 9-December 31, 2017. Data were collected using state-issued phones. Generic iPhonesApple SE models - with minimal data plans were deployed in 12 motor pool vehicles. Phones issued to employees were used to track data for the six remaining vehicles. For these drivers, Sawatch was able to evaluate driver behavior in addition to vehicle performance because these phones remained with individual drivers rather than in a vehicle. For the motor pool vehicles, about half-way through the data collection period, Sawatch noticed inconsistencies with data collection due to removal of the Bluetooth beacons from the car charging ports. To combat this, Sawatch installed the consumer-facing ezEV app - instead of the fleet version, which relies on beacons - to eliminate the need for the beacons. From October 1 through December 31, 2017, PTRTelematics captured nearly 700 hours of driving activity, 6,850 trips, and 12,400 miles of vehicle telemetry in the 12 monitored Colorado pool vehicles. During the entire pilot period, PTRTelematics captured nearly 750 hours of driving activity, 4,300 trips, and 17,500 miles of vehicle telemetry in the six monitored Colorado vehicles assigned to individuals.

Excluding trips that were missed due to human error (removing or disabling a cell phone or beacon device, which occurred more frequently in the pool vehicles), an initial hardware/software failure of approximately $10 \%$ was observed, a portion of which was a function of short trips falling below the software's capture thresholds. By revising the threshold size, the failure rate improved to as low as approximately $4 \%$.

\subsubsection{Fleet Characteristics}

Vehicles from three departments participated in the analysis for Colorado: Department of Natural Resources (DNR) Division of Parks \& Wildlife (St. Vrain and Barr Lake State Parks), Department of Labor and Employment (DLE) Division of Oil and Public Safety, and the Department of Personnel \& Administration Division of Capital Assets' motor pool. These vehicles averaged 1,664 miles during the 144-day study data period (see Table 13). Note that data collection started and stopped at different times for each of the three different sets of vehicles analyzed for Colorado. These vehicles drove a relatively large number of miles, presenting opportunities and challenges for a transition to EVs. Further, the VMT were not evenly distributed across vehicles, ranging from 8 to 4,440 miles during this period. Trips per vehicle ranged from 46 to 1,387 . Average trip lengths ranged from 0.1 miles to 14.3 miles. Table 13 shows the use summary for each vehicle covered in this analysis.

The Colorado drivers exhibited a wide range of driving patterns representing both large and more compact operational geographies and frequency of driving. Data collection spanned a large 
portion of the State of Colorado. While the vast majority of travel took place in or very near the Denver metropolitan area and the nearby Front Range, trips were recorded to all parts of the state, including rural and mountainous destinations as far as Durango (340 miles from Denver), Grand Junction (240 miles), Alamosa (235 miles), Craig (200 miles), Walden (140 miles), Sterling (130 miles), Burlington (170 miles), and La Junta (180 miles). Outside the Front Range of Colorado, access to EVSE is limited and often unavailable in rural areas and small towns.

Table 13. Individual Vehicle Use Averages for Colorado, June 1-September 1, 2017

\begin{tabular}{|c|c|c|c|c|c|}
\hline Driver & $\begin{array}{l}\text { Year, Make, } \\
\text { Model }\end{array}$ & Trips & $\begin{array}{l}\text { Avg. } \\
\text { Days in } \\
\text { Operation } \\
\text { (per veh) }\end{array}$ & $\begin{array}{l}\text { Total } \\
\text { VMT }\end{array}$ & $\begin{array}{l}\text { Est. Fuel } \\
\text { Use (gal) }\end{array}$ \\
\hline St. Vrain SP & 2008 Ford F250 & 1,046 & 84 & 1,645 & 220 \\
\hline Barr Lake SP & 2008 Ford F150 & 472 & 37 & 1,520 & 120 \\
\hline $\begin{array}{l}\text { DLE } \\
\text { Amuse/Explo }\end{array}$ & $\begin{array}{l}2016 \text { Ford Fusion } \\
\text { Hybrid }\end{array}$ & 400 & 42 & 2,827 & 89 \\
\hline DLE Boiler 1 & $\begin{array}{l}2015 \text { Jeep } \\
\text { Cherokee }\end{array}$ & 754 & 78 & 4,439 & 185 \\
\hline DLE Boiler 2 & 2014 Ford Fusion & 990 & 63 & 3,668 & 143 \\
\hline DLE Boiler 3 & $\begin{array}{l}2009 \text { Chevrolet } \\
\text { Impala }\end{array}$ & 657 & 53 & 3,404 & 170 \\
\hline Pool 1 & $\begin{array}{l}2015 \text { Chevrolet } \\
\text { Impala }\end{array}$ & 442 & 19 & 757 & 38 \\
\hline Pool 2 & $\begin{array}{l}2009 \text { Chevrolet } \\
\text { Impala }\end{array}$ & 191 & 19 & 649 & 27 \\
\hline Pool 3 & $\begin{array}{l}2014 \text { Dodge } \\
\text { Durango }\end{array}$ & 288 & 29 & 1,445 & 65 \\
\hline Pool 4 & $\begin{array}{l}2010 \text { Chevrolet } \\
\text { Impala }\end{array}$ & 149 & 11 & 734 & 32 \\
\hline Pool 5 & $\begin{array}{l}2015 \text { Chevrolet } \\
\text { Impala }\end{array}$ & 1,185 & 29 & 1,555 & 91 \\
\hline Pool 6 & $\begin{array}{l}2008 \text { Chevrolet } \\
\text { Uplander }\end{array}$ & 839 & 37 & 2,009 & 112 \\
\hline Pool 7 & $\begin{array}{l}2013 \text { Dodge } \\
\text { Durango }\end{array}$ & 318 & 11 & 34 & 14 \\
\hline Pool 8 & $\begin{array}{l}2010 \text { Chevrolet } \\
\text { Impala }\end{array}$ & 533 & 27 & 1,237 & 66 \\
\hline Pool 9 & $\begin{array}{l}2009 \text { Chevrolet } \\
\text { Impala }\end{array}$ & 1,387 & 41 & 1,001 & 56 \\
\hline Pool 10 & $\begin{array}{l}2015 \text { Chevrolet } \\
\text { Equinox }\end{array}$ & 46 & 10 & 8 & 2 \\
\hline Pool 11 & $\begin{array}{l}2009 \text { Chevrolet } \\
\text { Impala }\end{array}$ & 1,305 & 22 & 567 & 64 \\
\hline
\end{tabular}




\begin{tabular}{llllll}
\hline Driver & $\begin{array}{l}\text { Year, Make, } \\
\text { Model }\end{array}$ & Trips & $\begin{array}{l}\text { Avg. } \\
\text { Days in } \\
\text { Operation } \\
\text { (per veh) }\end{array}$ & $\begin{array}{l}\text { Total } \\
\text { VMT }\end{array}$ & $\begin{array}{l}\text { Est. Fuel } \\
\text { Use (gal) }\end{array}$ \\
\hline Pool 12 & $\begin{array}{l}\text { 2014 Dodge } \\
\text { Durango }\end{array}$ & 170 & 29 & 2,429 & 106 \\
\hline TOTALS & & 11,172 & 641 & 29,926 & 1,953 \\
\hline
\end{tabular}

\subsubsection{Colorado EVSA Results and Recommendations}

This section describes the results of the EVSA for each vehicle included in the Colorado pilot project. Table 14 summarizes the recommended EV replacement as well as the infrastructure access available to, or needed by, each Colorado vehicle for overnight charging. The EVSA were completed within DNR's Division of Parks \& Wildlife and, more specifically, with one employee at St. Vrain State Park and one at Barr Lake State Park from August 9 through December 31. Both parks are located just north of Denver and are relatively small in terms of their geographic footprint: St. Vrain is $1.075 \mathrm{mi}^{2}$ while Barr Lake is $4.242 \mathrm{mi}^{2}{ }^{2}$ The small geographic footprint is critical because the majority of the driving needs of these employees take place within or very near the park boundaries. At Barr Lake, 59\% of driving data were collected within 5 miles of the park, while $61 \%$ of driving data were collected within 5 miles of St. Vrain State Park.

Table 14. EV and EVSE Recommendations for Colorado Vehicles

\begin{tabular}{llll}
\hline Vehicle ID & Department & $\begin{array}{l}\text { EV } \\
\text { Recommendations }\end{array}$ & Infrastructure Needs \\
\hline St. Vrain SP & DNR - State Parks & Chevrolet Bolt & Needs: St. Vrain SP \\
Barr Lake SP & DNR - State Parks & Chevrolet Bolt & Needs: Barr Lake SP \\
DLE & DLE & PHEV & Needs: residential \\
Amuse/Explo & & PHEV & Needs: residential \\
DLE Boiler 1 & DLE & PHEV & Needs: residential \\
DLE Boiler 2 & DLE & PHEV & Needs: residential \\
DLE Boiler 3 & DLE & &
\end{tabular}

Driving data that were collected at further distances from the parks typically included longer distance trips to other parks or to various locations around either the Denver or Fort Collins metropolitan areas. Even with these long-distance trips, the 2018 Chevrolet Bolt could meet the driving needs of these State Park vehicles without ever needing access to midday charging. However, it is important to note that trips to other parks did include overnight travel in a handful of instances. Based on the duration of those stays, it would be possible for the drivers to charge those vehicles overnight at park facilities to complete the return trip, even on a Level 1 charger. These vehicles are very well suited for transition to EVs, based on these drive cycles.

Operational characteristics that this analysis is not able to account for are the passenger/cargo carrying and/or towing needs of these vehicles. Because both vehicles are pickup trucks, we assume that there is some regular need to carry cargo and/or tow trailers around the park. Of course, existing sedan options cannot replicate this mission capability, and it is therefore 
recommended that the parks continue to use the necessary vehicles for these purposes and replace all other travel with an EV.

The EVSA were completed for DLE's Division of Oil and Public Safety based on data collected from August 16 through December 31. Whereas the DNR vehicles analyzed exhibited a relatively compact geographic footprint and need in terms of the range of the vehicles, the DLE vehicles showed the opposite. They all had frequent days with long-distance travel to rural parts of Colorado, as well as overnight trips to some of the destinations mentioned earlier.

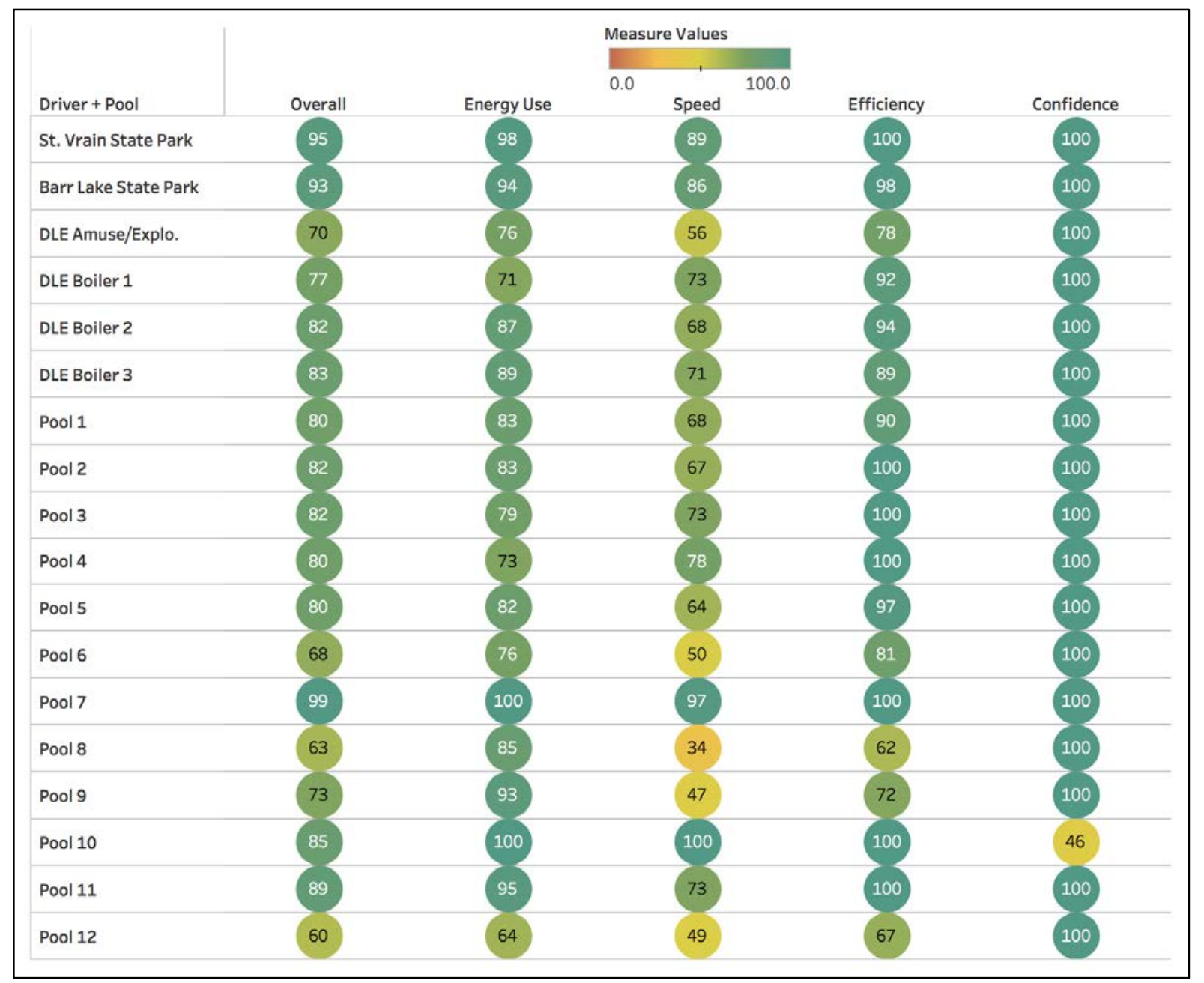

Figure 4. EV Suitability scores by vehicle for Colorado

The other major difference between these two sets of drivers was the frequency with which their vehicles parked overnight at residential locations. All four of the DLE vehicles analyzed parked overnight at residential locations the majority of the time. While this is not problematic in and of itself, it may present some logistical challenges in terms of charging vehicles using electricity from the employees' residences and for which the employees pay. Colorado should investigate the ability to have drivers fuel their vehicles using electricity from the residences and/or the ability to reimburse those employees.

Within the Amuse/Explo fleet, the 2016 Ford Fusion would have required more energy use than is available in a 2018 Ford Focus BEV (28.5 kWh of usable energy) on one of every four days; 
even in a Chevrolet Bolt the driver would exhaust the vehicle's battery on one of every 10 days. Given the frequent long-distance travel, often to remote areas without access to EVSE, this vehicle would be best replaced by a PHEV like the Chevrolet Volt or Ford Fusion Energi. In a 2018 Chevrolet Volt, which has a larger battery, based on data collected from the Amuse/Explo vehicle, we estimate that this vehicle could drive approximately $45 \%$ of its miles on electricity. This assumes the vehicle is fully charged each morning and does not account for any midday charging.

Within the Boiler Inspection Division fleet, the 2015 Jeep Cherokee showed travel patterns similar to the Amuse/Explo vehicle, exceeding the energy use of a 2018 Ford Focus BEV approximately one-third of the time. This vehicle is also best suited to be replaced by a PHEV. In a 2018 Volt, Sawatch estimates that this vehicle could drive approximately $46 \%$ of its miles on electricity, assuming a full charge each morning and not accounting for midday charging.

The 2014 Ford Fusion in the Boiler Inspection Division fleet also had noticeable long-distance travel but would have exceeded the energy use of the Focus BEV on only $14 \%$ of days and of the Chevrolet Bolt on only two out of 63 days. With some careful management of long-distance and overnight travel, this driver could be well suited for a Chevrolet Bolt; but, given the frequency of travel in the central mountains, it may be best suited to a PHEV. In a 2018 Volt, this vehicle could drive approximately $64 \%$ of its miles on electricity, assuming a full charge each morning and not accounting for midday charging potential.

The 2009 Chevrolet Impala in the Boiler Inspection Division fleet had results very similar to the Boiler Inspection Division's 2014 Ford Fusion, with approximately 13\% of days in which it would have exceeded the energy use of the Fusion BEV, and only $6 \%$ of days if a Chevrolet Bolt had been driven. This driver could also function well in a Chevrolet Bolt; in a 2018 Volt, this vehicle could drive approximately $58 \%$ of its miles on electricity, assuming a full charge each morning and not accounting for midday charging potential.

For the Motor Pool vehicles, the ezEV results showed mixed results. Only four of the 12 exhibited energy scores above 90, and every vehicle for which data were collected experienced long-distance travel outside the Denver area. In addition, at the time the data were collected, the State had already assigned several EVs — one Ford Focus BEV and five Ford Fusion Energi PHEVs - to the same motor pool. Despite each vehicle having very high utilization on some days, none experienced that usage on all days, and the high usage did not necessarily happen on the same days across all vehicles. In a motor pool context, it is important to see the utilization of all assets and the broader context of travel needs of employees. Such a context might allow for improved oversight or management that would assign certain types of trips to the appropriate technology - EV, PHEV, or ICE - and inform the ability to make recommendations around the right mix of vehicle technologies to meet employee needs. This will be the topic of future research.

\subsubsection{EVSE Recommendations}

To support the implementation of a successful transition to EVs, the State of Colorado will need to consider the installation of additional EVSE. The motor pool vehicles already have access to charging at the downtown Denver motor pool parking lot, but those chargers are currently being used by existing EVs, so additional charging capacity may be necessary to support any additional EVs brought into the pool. 
With plenty of open space and parking as well as electrical infrastructure supporting recreational vehicles, the state parks should be able to facilitate installation of charging stations with relative ease. In this context, the addition of charging stations at the parks has the added benefit of providing an additional amenity to park visitors. While this pilot project was being completed, the Parks Department was in the process of installing EVSE at Cherry Creek State Park; this is ultimately where the state decided to assign an incoming 2018 Chevrolet Bolt.

For the DLE and Boiler Inspection Division vehicles, the difficulties of managing charging at residential locations meant that neither BEVs nor PHEVs were ultimately recommended. Accordingly, there are no recommendations for the installation of EVSE at these residential locations or elsewhere at DLE facilities at the time of this analysis.

\subsubsection{Colorado Lessons Learned}

The Colorado pilot project provided a different view of fleet operations and needs within a very large organization with travel needs spread out across a large geographic area. This pilot project was similar to the LDEQ project in terms of a large geographic footprint, but also illustrated the varying travel needs of different departments within a state government. Travel for state park employees looked very different than it did for the Boiler Inspection Division; in the latter case, the results of the effort led to a decision not to pursue EVs at this time.

The motor pool experience in Colorado was also revealing in the sense that it exposed the possibility of looking at a set of vehicles and travel needs of employees in combination to find opportunities for gains in efficiency. Because the vehicles can be effectively checked out at a moment's notice, it is difficult to predict how often the travel needs will exceed the capabilities of an EV. This can be a difficult management problem to solve and complicates the adoption of EVs if all vehicles need to be capable of facilitating the longest trips on demand. However, with additional information about employee travel needs, it is possible to start considering an optimal mix of vehicle technologies where the right technology is used for the appropriate trips, which might require additional oversight or management of trip scheduling. 


\section{Conclusions and Next Steps}

In support of fleets mandated under EPAct to acquire alternative fuel vehicles or otherwise implement strategies to increase alternative fuel use in covered fleet vehicles, Sawatch and NREL partnered on a series of pilot projects to analyze fleet vehicle suitability for transition to EVs. Such analyses could be used to justify investments in EVs and associated EVSE. Working with a diverse set of fleets offered the opportunity to test data collection and analytic methodologies across different telematics providers to better understand the strengths, weaknesses, and possibilities for employing different data collection methods.

Data were collected from five EPAct-covered fleets that included vehicles from four different state fleets (Louisiana, Connecticut, Rhode Island, and Colorado) and one utility fleet (Florida Power \& Light). Each pilot project employed slightly different data collection methods that used a combination of both smartphone-based telematics and more traditional telematics with hardware installed on the vehicles. These experiences revealed two primary conclusions:

- Smartphone-based telematics can provide a low-cost option for telemetry data capture relative to hardware-based counterparts. The primary advantage of smartphone data capture is the lower costs to collect and transmit data through devices that are nearly ubiquitous. This process does not require purchase of additional hardware and associated data plans. Using the hardware already present in drivers' pockets results in trivial data collection and transmission costs. The downside of this data collection method is the human element, which precludes reliability in data capture-to always have the phone present and charged and with Bluetooth and location services enabled. Any one or a combination of these failures causes interruption in data collection and a drop in the resulting confidence associated with the analytic results.

- Where smartphones can supplement traditional telematics, the quality of the data - in terms of granularity and accuracy - is on par with traditional telematics. However, this fact is greatly affected by the smartphone quality, as experienced with the use of lowerend, inexpensive devices used in the Rhode Island pilot project. As a result, data collection efforts via smartphone may be compromised when there is uncertainty as to the types of devices spread across a set of drivers.

A complementary finding of the effort to compare data collection options for fleets was the ability to apply ezEV analytics to any of the resulting data streams. As the pilot projects progressed, the analytics framework was adjusted to account for differences in the data streams while preserving the core outputs. As a result, the Sawatch analytics evolved into a data-sourceagnostic analytics platform capable managing a telematics data stream regardless of the data provider. This enables fleets that have already made an investment in telematics to leverage those efforts to access those analytics without having to re-collect data through another means.

The diversity of EPAct-covered fleets participating in the pilots addressed in this report also revealed interesting and varied opportunities and challenges regarding the adoption of EVs into regulated fleets. Geography appears to play the most critical role - whether to recommend EVs requires understanding the size of the area in which a vehicle operates. Smaller, constrained 
geographies like the FPL service territories and the UCONN campus environment are particularly well suited for EVs, particularly where other specialized needs are also absent (e.g., cargo, passenger carrying needs). On the other hand, the larger geographic footprints that the Colorado and Louisiana state vehicles cover limit the viability of EVs - at least in the near-term, in one-for-one replacements. As EV battery technology improves, all-electric driving ranges increase, and EVSE availability expands, the opportunities to place EVs into use case with longdistance duty cycles will also increase. In the meantime, these state fleet pilots revealed the opportunity for fleets to consider an optimal mix of vehicle technologies, where the right miles are assigned to the right vehicle technology instead of having employees simply sign out for use whichever vehicle is available, or whichever vehicle they prefer.

The results of this study suggest additional lines of inquiry that might best be explored with the Colorado fleet specifically given its critical mass of EVs in operation. Such an examination would seek to: (1) demonstrate the value of collecting, analyzing, and monitoring EV-specific data related to vehicle state-of-charge and charging patterns; (2) compare real-world vehicle performance to ezEV estimates; (3) validate the ability of fleets to incorporate new technologye.g., kWh consumption and electricity costs alongside gasoline consumption and costs - into existing accounting/financial systems; and (4) establish best practices that help ensure overall costs of integrating new vehicle technologies remain at or below cost parity with existing technologies. 